\title{
“CONSUMER MOTIVATION FOR PRODUCT DISPOSAL AND ITS ROLE IN ACQUIRING PRODUCTS FOR REUSE”
}

\author{
Dayna Simpson \\ Department of Management \\ Monash University \\ Caulfield East, Victoria, Australia \\ Dayna.Simpson@monash.edu $^{1}$ \\ Damien Power \\ Department of Management and Marketing \\ University of Melbourne \\ Parkville, Victoria, Australia; \\ University of Groningen, Groningen, NL \\ damien@unimelb.edu.au \\ Kathleen Riach \\ Department of Management \\ Monash University \\ Caulfield East, Victoria, Australia \\ University of Glasgow, Glasgow, UK \\ Kathleen.Riach@monash.edu \\ Yelena Tsarenko \\ Department of Marketing \\ Monash University \\ Caulfield East, Victoria, Australia \\ Yelena.Tsarenko@monash.edu
}

\section{INTRODUCTION}

To ensure profitable product reuse, it is vital for consumers to dispose of reusable products while they are still in good working condition (Blackburn, Guide, Souza and Van Wassenhove, 2004; Guide, Souza, Van Wassenhove and Blackburn, 2006; Ray, Boyaci and Aras, 2005). Early retirement of products by consumers, however, is

\footnotetext{
1 Corresponding Author
}

This is the author manuscript accepted for publication and has undergone full peer review but has not been through the copyediting, typesetting, pagination and proofreading process, which may lead to differences between this version and the Version of Record. Please cite this article as doi: NA

This article is protected by copyright. All rights reserved. 
somewhat of a paradox, given that when consumers purchase new products they do not expect to be replacing them anytime soon (if at all). In practice, manufacturers increasingly offer to buy consumers’ used products, as a means to increase new product sales, and support product reuse operations (e.g. Apple GiveBack and Samsung Trade Up). Such programs, including trade-ins, online auctions, individual selling, and recycling, reflect a growing number of ways in which firms can connect directly with consumers to acquire product and encourage upgrades by consumers (Srivastava and Chakravarti, 2011; Kim, Rao, Kim and Rao, 2011; Hahler and Fleischmann, 2017). Research in this space, however, particularly regarding how firms might more cost-effectively acquire products from consumers, rarely draws from the behavior of actual consumers. This is surprising, given much of the uncertainty in product acquisition relates directly to the choices of consumers (Guide, 2000; Klausner and Hendrickson, 2000; Galbreth and Blackburn, 2010).

Product reuse is a multi-billion dollar industry that reduces pollution by collecting goods for reuse, rather than landfill, as well as decreasing firms' reliance on nonrenewable resources (Abbey, Meloy, Blackburn and Guide, 2015; UNEP, 2015; Esenduran, Kemahlioglu-Ziya and Swaminathan, 2016). In the literature regarding how manufacturers should acquire products for reuse, however, consumer behavior is addressed only to the extent that consumers “return” some products under retailers' return policies (Ferguson, Guide and Souza, 2006). Returns represent only a small proportion (5-10\%) of all products purchased by consumers (Ferguson et al., 2006). 
They are a very limited subset of products, given they arise under retailer policies, that typically cover only a 30, 90 or 180 day post-purchase period. This focus on returns therefore has two major limitations: first, a vast number of products still have significant value beyond the period, and conditions, of product return policies; second, the psychology of product returns is fundamentally different to the psychology of “disposal”, in which consumers must relinquish a product for which they have a sense of ownership (Okada, 2001; Coulter and Ligas, 2003).

For their part, consumers often view their possessions as personal and financial extensions of the 'self'. Product ownership is influenced significantly by a consumer's own psychological characteristics, as well as a bond that can exist between consumer and product (Lastovicka and Sirianni, 2011; Haws, Naylor, Coulter and Bearden, 2012; Brough and Isaac, 2012). Tension arises where a consumer perceives greater value in product ownership, than what they could emotionally or financially gain from product disposal (Okada, 2001; Bellezza, Ackerman and Gino, 2017). A fundamental premise of past research on product disposal is that while consumers may struggle to give up possessions (Kleine and Baker, 2004; Haws et al., 2012), they are also open to disposal methods that compensate psychological loss with psychological gain (Lastovicka and Fernandez, 2005; White, MacDonnell and Dahl, 2011; Sun and Trudel, 2017). Consumers have been shown to engage with disposal more willingly, where the action can help others, reduce pollution, or allow them to move on from the past (Jacoby, Berning and 
Dietvorst, 1977; Lastovicka and Fernandez, 2005). Prior research has paid little attention, however, to how consumers manage the disposal of products with high reuse value. Reusable products, such as automobiles, electronics, or household appliances have: "benefits [that are] spread out over future periods [and] utility does not diminish significantly in successive usage occasions.” (Okada, 2001: p.434). Their capacity for use over a long period of time may increase a consumer's dependence on the product (Chandler and Schwarz, 2010). In addition, that a product 'still works' increases tensions for a consumer given that disposal, regardless of when, suggests that something will be wasted (Arkes, 1996; Brough and Isaac, 2012).

From the manufacturer's perspective, used product acquisition involves significant uncertainty. The ability to predict the quality and quantity of what is being acquired is a constant problem. Prior scholarship for the most part, suggests that firms should deal with this uncertainty through their relationships with suppliers, or by increasing their control over how products are collected (Guide and Van Wassenhove, 2001; Savaskan, Bhattacharya and Van Wassenhove 2004; Atasu, Toktay and Van Wassenhove 2013; Hahler and Fleischmann, 2017). While these practices have helped to reduce uncertainty in used product supply, they neglect the fundamental role of consumers. As such, better understanding of consumer behavior in advance of product acquisition, offers scope for manufacturers to improve the quality of products acquired for reuse, and reduce costs. For example, products acquired earlier in their life cycle, or in greater volume, allow manufacturers to spread their costs over more 
units (Ovchinnikov, 2011). It also improves the choices manufacturers have regarding how to profit from reuse, and end-of-life product collection (Klausner and Hendrickson, 2000; Seitz, 2007; Atasu, Guide and Van Wassenhove, 2010; Atasu and Van Wassenhove, 2012).

To our knowledge there are no behavioral studies in the product acquisition literature that deal directly with consumers, before or during product disposal. This has been noted by others, who have called for more consumer-focused research in this domain (Rao, Narasimhan and John, 2009; Souza, 2013; Abbey, Meloy, Guide and Atalay, 2015). In our research, we explore: a. consumer beliefs around product ownership and disposal; and b. its implications for manufacturers seeking to acquire product for reuse. We do so with three studies involving consumers: i. consumer in-depth interviews ( $n=19)$; ii. a consumer survey $(n=250)$; and iii. a behavioral experiment with consumers $(n=382)$. We found that by offering two key psychological rewards financial and emotional - consumers were more willing to relinquish high quality products for disposal, and would in some circumstances do so for less in return. In particular, consumers' under-utilization of a product, and disposal options that offered them an emotional reward (giving to charity), were significant motivating factors for disposal. These findings contribute significantly to the literature on product acquisition, but also to behavioral theories surrounding product disposition. Our findings also allow us to offer several practical implications for manufacturers, with

This article is protected by copyright. All rights reserved. 
respect to how they can develop consumer-focused programs to acquire ideal products for reuse.

\section{BACKGROUND AND RESEARCH OVERVIEW}

\subsection{Background}

Product acquisition is the process through which firms seek to acquire products for reuse (Guide, 2000). It is a critical first step for reuse operations that influences the quality of products available as well as product volume and the costs of collection (Guide and Van Wassenhove, 2001; Galbreth and Blackburn, 2010). Reusable products are sourced indirectly and directly by firms, from consumers and businesses through a variety of different methods. Product acquisition is an intentionally proactive process, and it advocates for control over how firms obtain reusable products rather than waiting for them to become available through more exogenous forces (Guide and Jayaraman, 2000; Guide and Van Wassenhove, 2001). The literature on product acquisition addresses a wide range of issues relevant to how firms can acquire optimal product for reuse. These include issues relevant to purchasing (Hahler and Fleischmann, 2017), volume (Galbreth and Blackburn, 2010), forecasting (Clottey, Benton and Srivastava, 2012), quality (Ray et al., 2005; Ovchinnikov, 2011), pricing (Ray et al., 2005), collection (Savaskan et al., 2004; Atasu et al., 2013) and competition (Ferguson and Toktay, 2006). 
Prior scholarship on product acquisition, however, addresses only the behavior of firms and their industrial networks. Although this remains important for reducing uncertainty in the supply of reusable products, the manufacturer is still one or more stages removed from the product-source: an actual consumer. While significant prior work deals with consumers in how they generate "returns", given that returns are not strictly used products, they are driven by psychological motivations of less relevance to product disposal. Returns are acquired because product defects, product ordering errors, or “false” failures such as a buyer’s remorse, lead consumers to reject products (Ferguson et al., 2006; Griffis, Rao, Goldsby and Niranjan, 2012; Shang, Pekgun, Ferguson and Galbreth, 2017).

From a consumer's perspective, disposal marks the end of product ownership and as such, it has psychological implications. Disposal can be a particularly negative process for a consumer as it involves either loss of a possession that has emotional value, or because a valued resource will be wasted (Coulter and Ligas, 2003; Lastovicka and Sirianni, 2011). Disposal can also, however, be a positive process for consumers if it is rewarding in some way - such as through emotional or financial gain. Psychologically positive disposal could encourage consumers to dispose of products sooner (Lastovicka and Fernandez, 2005; Ture, 2014; Sun and Trudel, 2017; Bellezza et al., 2017), and in many cases at reduced costs for a manufacturer (Okada, 2001). As we propose in our research, while consumers may have reasons to retain products, certain rewards for disposal can still weaken psychological ownership, and 
help to increase disposal by consumers in ways that favor the goals of product acquisition.

\subsection{Research overview}

To develop our hypotheses, we conducted three separate studies as outlined in the conceptual framework shown in figure 1. In our first Study, in which we conducted in-depth interviews with consumers, we sought to understand how consumers' psychological characteristics will motivate both retention and disposal of reusable products. In Study 2, we tested hypotheses relevant to product retention, with a survey of a cross-sectional sample of 250 consumers. Following this, we developed further hypotheses relevant to product disposal and conducted a third Study in which we provided an experimental scenario to 382 consumers. In this, we explored hypothetical incentives for disposal and the extent to which these were undermined or supported by consumers’ psychological characteristics.

\section{--- FIGURE 1 HERE ---}

In each of our studies, we used personal computers as the product of interest (e.g. desktop computers, laptops or tablets), with specific attention on laptops in the final study. Computers are 'reusable' products, have reuse value well beyond a single model cycle and are designed to last for several years. Consumers are able to upgrade to new models earlier than this, however, and from the manufacturer's perspective, preferably on an annual basis. The length of time that consumers typically own personal computers for, however, can be significantly different to a manufacturer's

This article is protected by copyright. All rights reserved. 
expectations. Consumers have been shown to keep multiple generations of computers at any one time and hold onto them for up to 6 years per unit (Saphores, Nixon, Ogunseitan and Shapiro, 2009; Sabbaghi, Esmaeilian, Mashhadi, Behdad and Cade, 2015). Estimates of consumer household ownership, indicates from three to five personal computers per household, with old products being exchanged among household members, and not being replaced (Shih and Venkatesh, 2004; EPA, 2011). The implications of this are that the availability of many products for timely commercial reuse (e.g. remanufacturing) may be substantially lower than expected. Computers also present increased risks of improper disposal as they age (Babbitt, Williams and Kahhat, 2011; Atasu and Souza, 2013; Lam, Lim and Schoenung, 2013). Therefore, from both an economic and environmental perspective, consumers' personal computers are an ideal product for exploring behavior around product ownership and disposal.

\section{PRODUCT RETENTION}

We sought first, to identify consumers’ specific psychological motivations for extending ownership of reusable products, and to what extent this varied with product use and product age. Reusable products provide function and enjoyment in consumers' lives, but can also act as support for a consumer's self-concept (Kleine, Kleine and Allen, 1995; Kleine and Baker, 2004; Palmer, 2009). Consumers are therefore likely to assign meaning to reusable products as much as they would with any other product (Belk, 1988). For some consumers, the tendency to form bonds 
with or hold strong beliefs about the purpose and value of products (or the resources associated with them) may be higher than others. Such consumers are potentially more prone to product retention, understood as: “an individual's general propensity to retain consumption-related possessions” (Haws et al., 2012:p.224). As we initially propose, consumer's underlying beliefs interact with the characteristics of reusable products to increase their resistance to disposal.

\subsection{Study 1}

We interviewed a group of consumers in Australia $(n=19)$, asking them open-ended questions about the number of computers they owned, why they kept their old computers, and what would motivate them to dispose of them. We recruited participants through advertisements placed on university noticeboards and social networking sites. We also asked participants to introduce us to other individuals (snowballing). Participants represented a range of incomes, ages (25 to 53), and nationalities, and all had college-level education. Interviews lasted for approximately 40 minutes each. We analyzed transcribed interviews with NVivo11, and used a recommended two-stage process of analysis (e.g. Pratt, Rockmann and Kaufmann, 2006; Gioia, Corley and Hamilton, 2012). Stage 1 aimed to "give voice to the informants” (Gioia et al., 2012:p.17) through inductive coding using participant’s evocative words and phrases to develop initial codes. 64 first order codes were generated during this stage, and amalgamated into 51 codes after searching for replication. Stage 2 identified more abstract theoretical processes across the corpus 
such as unspoken logics that shape participant actions (Gioia et al., 2012:p.21). Our analysis produced 2 macro-order, and 5 second-order themes relevant to consumers' reasons for product retention, and disposal (table 1).

\section{---TABLE 1---}

Consumers' reasons for retention converged on three themes: emotional associations with the product (e.g. support for identity, or sentimental value); extending the product's useful life (e.g. by repurposing or reuse by others); and a computer's importance through constant use, across a range of tasks. The first two factors (emotional and extension themes) reflected two consumer behaviors. The first is concerned with tendencies of attachment, including behaviors such as overvaluing (Dommer and Swaminathan, 2012; Norton, Mochon and Ariely, 2012), identity associations (Phillips and Sego, 2011), and product “friendship” (Chandler and Schwarz, 2010). In the second, consumers tended toward product usage and reuse behaviors that reflected ideals of thriftiness, frugality and being waste averse (Bolton and Alba, 2012; Lastovicka, Bettencourt, Hughner and Kuntze, 1999). The third factor (frequent use) suggested an alignment with the characteristics of reusable products - that products were important because they could be used regularly, and across a wide range of tasks.

Consumer's reasons for disposal converged on two themes: disposal motivated by the potential to help others, such as donating the product to family, friends or charity; and 
disposal involving a beneficial exchange, such as an upgrade or some other financial benefit.

\subsection{Development of hypotheses}

\subsubsection{Attachment}

Product attachment occurs where consumers feel a strong sense of ownership for a possession (Belk, 1988; Kleine and Baker, 2004; Haws et al., 2012). Attachment is understood as a: "psychological or emotional connection between [consumer] selfconcept and a tangible product” (Brough and Isaac, 2012:p.79). Attachment arises where consumers form associations with possessions, fusing their personal goals and beliefs to products and elevating a product's non-economic values. High attachment is linked to behaviors in which consumers seek to largely avoid product disposal, or expect unrealistic prices for products they try to sell to others (Srivastava and Chakravarti, 2011; Palmer, 2009; Brough and Isaac, 2012; Dommer and Swaminathan, 2012). Attachment increases with simple actions such as touching a product (Peck and Shu, 2009), anticipating a product before purchase (Lastovicka and Sirianni, 2011), or having involvement in product construction (Norton et al., 2012). It can be higher for products that were purchased or owned during a significant life event, such as during one's youth, or after a divorce (Kahneman, Knetsch, and Thaler, 1990; Dommer and Swaminathan, 2012). Attachment can also increase with product history (Curasi, Price and Arnould, 2004), and is strongly associated with consumer identity (Kleine et al., 1995; Phillips and Sego, 2011). 
The role of attachment is a complicating factor in product disposal, and its role in the disposal of reusable products in particular, has received limited attention. Attachment has been linked primarily to possessions that intuitively invoke emotional associations, such as gifts, children's clothing, collectables or family heirlooms. The effect of attachment on products that can be upgraded well before they reach the end of their lifespan, however, (e.g. cell phones, appliances, and automobiles) is unclear. The long life cycle of reusable products too, potentially increases rather than discourages dependence on the product (Chandler and Schwarz, 2010). As we found in Study 1, consumers readily assigned meaning to their personal computer, referring to them as friends, 'essential', or as repositories of history. This suggests that reusable products are also prone to attachment where they can be personalised, or store information, or that their portability allows consumers to travel with them. In short, there is ample reason to assume that ownership of reusable products is influenced by consumer predisposition toward product attachment. Given this, our first hypothesis is as follows:

H1a. Consumers with increased attachment tendencies will be more likely to seek retention of reusable products.

\subsubsection{Frugality}

A consumer's aversion to waste, particularly financial waste, is also proposed to 
impact a consumer's willingness to dispose of products. How a consumer's propensity to be frugal affects product ownership and the role it plays in influencing product disposal has received little empirical attention. Haws et al. (2012) used the following example to describe how a product's capacity for reuse can limit product disposal:

"Steve thinks that throwing away goods that have some residual value is wasteful. He believes that getting rid of his old sofa, now carefully stored in the attic, would be frivolous, and he keeps a broken bike in the garage because he might need the chains to repair another bike or the gears to make a motorized scooter.” (p.224).

Frugality (Lastovicka et al., 1999) is an example of a consumer belief that encourages individuals to extend a product's life, as a means to save money. Frugal tendencies are closely correlated with “restrained product use behaviors” (Lastovicka et al., 1999; Evers, Gruner, Sneddon and Lee, 2018). As Lastovicka et al. (1999:p.96) define it, frugality is: “... sacrifice in denying a series of short-term purchasing whims and industriousness by resourcefully using what is already owned or available for use; all of this is in service of achieving longer term goals”. Consumers do not like waste, and to be wasteful is to be associated with spending more than we need to, or not getting one’s money's worth from a product (Arkes, 1996; Okada, 2001). As we identified in Study 1, consumers were reluctant to dispose of personal computers that still worked, choosing instead to repurpose them or 'save' them for a future, unknown use. 
Although frugality is not the same as materialism or environmentalism (Haws et al., 2012; Evers et al., 2018), it is still likely to encourage extended use of products, where they still work, and can reduce the need for further purchases (Bolton and Alba, 2012). As such, we expect that a consumer's frugal beliefs will encourage longer periods of product ownership, and a greater reluctance to dispose of a reusable product. Thus our second hypothesis is that:

H1b. Consumers with increased frugality will be more likely to seek retention of reusable products.

\subsubsection{Frequent use and product age}

In addition to psychological drivers of retention, the characteristics of reusable products - an infinite number of uses over a lengthy lifespan - are proposed to also influence product retention and disposal. Prior research suggests that products generally decline in value for consumers over time (Heath and Fenema, 1996; Gourville and Soman, 1998). This is based on the likelihood that technology and quality depreciate with time, and a better upgrade or replacement model will be available in the future. From a mental accounting perspective, consumers are expected to deduct value from a product with each use, reducing product value to zero over time (Thaler, 1999; Okada, 2001; Desai, Purohit and Zhou, 2016). As such, greater product use allows a consumer to feel that they have “gotten their money’s worth” from a product (Okada, 2001; Ho, Png and Reza, 2018). Infrequent use of a product is 
assumed to equal a slower rate at which a consumer can pay down a mental debt, increasing resistance to disposal (Heath and Fenema, 1996; Okada, 2001). Thus frequent use, over time, has previously been described as inclining consumers toward greater product disposal, while conversely, a consumer is less inclined to dispose of under-utilized products.

While such assumptions have intuitive merit, they ignore the role of a consumer's psychological characteristics in product ownership. Increased product use may also create dependencies that encourage (rather than discourage) product retention. In particular, the literature on sunk costs highlight the various ways in which consumers value products after a purchase, and with use (Arkes and Blumer, 1985; Ho et al., 2018). Where a consumer has gained significant enjoyment from a product, particularly through regular or high quality use of the product, they may be more reluctant to dispose of the product (Okada, 2001). For example, a favorite pair of sneakers may be well past their use-by-date, but their reliability, history, or comfortable fit discourages a consumer from replacing them.

While frequent use may not always translate into reluctance to replace a product (products wear out eventually), it provides an opportunity for consumers to repeatedly interact and bond with, products (Okada, 2001; Chandler and Schwarz, 2010). For example, when consumers were told that a used car they were trying to sell had served them well “over the years”, they wanted more money to trade it in (Zhu, Chen 
and Dasgupta, 2008; Srivastava and Chakravarti, 2011). Over time, as opportunities for product associations and familiarity increase, a product's utility to the consumer may supersede product quality (Chandler and Schwarz, 2010). As we identified in Study 1, consumers referenced the importance of an often-used personal computer in their life. The scope for personal computers to perform several tasks, their portability, or their accessibility in the home, increases opportunities for consumers to depend on them. As our consumers described, frequent use was integral to the essential role of a computer in their lives. While frequent use on its own may not necessarily lead to product retention, it may still exacerbate retention where a consumer is predisposed to: a. form associations with products, or b. seek to extend the life of their purchases. Thus frequent use is proposed to interact with psychological characteristics, such as attachment or frugality, and further strengthen their effects. As time passes also, and the opportunities for product dependence from frequent use increase, the interaction should further promote retention. As such, we propose that:

H2a. More frequent use of reusable products will strengthen the effects of attachment and frugality on retention; and

H2b. This effect will increase as the period of product ownership increases.

\subsection{Study 2}


Drawing from the findings of Study 1, we developed a survey to empirically test the relationships between consumer psychological characteristics, product use and age, and product retention, for personal computers. We developed survey items by adapting existing constructs from the consumer psychology literature, focused on attachment and frugality, as well as additional product characteristics (such as frequency of use and product age). In Study 2, we surveyed a cross-sectional sample of consumers in Australia. We drew from a national database of consumers until obtaining a sample that was representative of national demographics across gender, age, income and education. Questions focused on a personal computer ${ }^{2}$ the consumer already owned. Consumers were asked initial screening questions to ensure that they owned at least one computer (e.g. a desktop, laptop or tablet). We also included an “attention check”, as detailed in the Appendix. A small number of consumers were dropped from the study because they failed the attention check. The final, screened sample of 250 consumers had the following characteristics: 49\% had an annual income over \$50,000 AUD; 50\% were aged 18-45 years; 54\% had at least college level education; and 54\% were female.

\subsubsection{Measurement}

We used five-point measurement scales for all items (1=strongly disagree, $5=$ =strongly agree) (full details provided in Appendix).

Attachment tendencies. Most prior studies of attachment use consumers’ meaningful possessions such as those that readily invoke sentimentality, or can be associated with

\footnotetext{
${ }^{2}$ Respondents reported ownership of: desktops ( $\left.n=118\right)$; laptops $(n=114)$; or tablets $(n=18)$.
} 
family history, such as children's clothing and gifts (Lastovicka and Fernandez, 2005; Lastovicka and Sirianni, 2011). Other studies have used products that can easily integrate identity or cultural associations (Kleine et al., 1995; Phillips and Sego, 2011). Specifically, Haws et al. (2012) sought to reduce the focus of emotional ownership on product meaning or emotional source by defining a set of everyday beliefs associated with difficulty discarding a broad range of products. Given this broader scope and potential application to reusable products, we used a four-item scale from Haws et al. (2012) to measure Attachment Tendencies.

Frugality. We sought a conceptualization that captured a consumer's aversion to monetary waste, specifically in relation to product use. As such we drew items from Lastovicka et al.'s (1999) eight-item scale. Of the original eight items, only four loaded appropriately at values above 0.70 and without cross loading with other factors. These four items aligned with a consumer's careful use of money and economizing, and were similar to other four-item solutions in recent work that used Lastovicka et al.'s (1999) scale (Goldsmith, Flynn and Clark, 2014; Evers et al., 2018).

Product retention. For our dependent variable we sought a direct measure of a consumer’s commitment to a product they owned, rather than general beliefs about product retention. As such, we used Lastovicka and Sirianni’s (2011) three-item measure for enduring commitment to a product, to capture Product Retention. Frequency of use 
As a first step, we asked consumers to identify the computer that was most important to them and still in use by them. We then asked 'why' this computer was most important and classified responses into two categories to indicate product importance based on usage. The two categories were coded as 'Frequent Use' (1'), or 'Other Use' (0). To confirm the two categories adequately represented frequent relative to lessfrequent use, we compared groups to an additional question regarding how often the computer was used across common tasks (after Shih and Venkatesh, 2004). The analysis indicated significantly higher product use, across all tasks, for consumers in the 'Frequent Use' group relative to consumers in the 'Other Use' group (full details in Appendix).

\section{Product age}

We asked for the age (in years) of each consumer's most important computer. The response range, and final variable breakdown was: 0.5 (47, 18.8\%); $1(34,13.6), 2$ (63, 25.2\%), 3 (48, 19.2\%), 4 (26, 10.4\%) and 5+ years (32, 12.8\%).

Control variables. We collected information for various control variables including consumers': Age, Income, Education, Gender and Number of Computers Owned (full details in Appendix).

\subsubsection{Results}

Of the consumers that completed the survey $(n=250)$, their demographics were as follows: 50\% owned at least 2 computers and on average owned 2.8 (SD 1.56) computers. $16 \%$ of the sample owned 4 computers, and $16 \%$ owned 5 or more. The mean age of a consumer's primary computer was 2.4 years (SD 1.48). For the three 
composite variables measured by Likert scale, we performed a confirmatory factor analysis (CFA) with results as follows: Attachment Tendencies $(M=3.15, S D=1.1$, $\alpha=0.93)$, Frugality $(M=3.97, S D=0.81, \alpha=0.90)$ and Product Retention $(M=3.65$, $S D=1.03, \alpha=0.78)$. The CFA was conducted using a maximum likelihood estimation and acceptable fit was demonstrated for all three variables (CFI=0.95; TLI $=0.94$; RMSEA=0.08) (full details in Appendix).

For analysis, we conducted a multiple regression (using SPSS v.25), with Product Retention as the dependent variable. The results (table 2) indicated a significant relationship between Attachment Tendencies and Product Retention $\left(p=0.003^{* *}\right)$, and between Frugality and Product Retention $\left(p=0.003^{* *}\right)$. Frequency of Use also had a significant effect on Product Retention ( $p=0.032 *)$, but Product Age did not significantly affect Product Retention. Of the control variables, only Education $\left(p=0.023^{*}\right)$ and Gender $\left(p=0.043^{*}\right)$ had a significant effect on Product Retention, while Income, Age and Number of Computers Owned were non-significant.

\section{--- TABLE 2 HERE ---}

In addition to the main effects described above, we assessed the interaction between Frequency of Use, Product Age and each of Attachment Tendencies and Frugality, on Product Retention. The total interaction was non-significant, however, several conditional effects were present (table 3). First, the effect of Frequency of Use on the relationship between Attachment Tendencies and Product Retention, regardless of 
Product Age, was significant for frequent use $\left(B^{3}: 0.239, p=0.001^{* *}\right)$, but nonsignificant for other use ( $B: 0.104, \mathrm{~ns})$. The effect of Frequency of Use on the relationship between Frugality and Product Retention, was also significant for frequent use $\left(B: 0.286, p=0.005^{* *}\right)$, and again, non-significant for other use $(B: 0.212$, ns). Second, the effect of Frequency of Use and Product Age combined (table 3), indicated that the effect of Attachment Tendencies on Product Retention was limited to computers older than 6-months, and only where they were also being frequently used. Similarly, increased Frugality only increased Product Retention for computers older than 6-months, irrespective of how frequently they were used. Across all product ages inspection of PROCESS results indicated that where computers were being frequently used, Attachment Tendencies’ effect on Product Retention was significant after 1.02 years of ownership $(p<0.05)$, with an increased effect after 1.62 years of ownership $(p<0.01)$, but declining in strength after 3.87 years $(p<0.05)$. Frugality's effect on Product Retention was significant after 1.44 years of computer ownership $(p<0.05)$, and with an increased effect after 2.07 years of computer ownership $(p<0.01)$.

\section{--- TABLE 3 HERE ---}

\subsubsection{Discussion}

Our results supported H1a and H1b, in which we proposed that increased tendencies toward Attachment or Frugality are related to increased retention of reusable products. In addition, our results also supported H2a and H2b, in which we expected

${ }^{3} B=$ Unstandardized coefficient.

This article is protected by copyright. All rights reserved. 
that Attachment Tendencies and Frugality would be more likely to increase Product Retention if the product was also being frequently used (H2a), and that this effect would strengthen as the time period for product ownership increased (H2b).

\section{PRODUCT DISPOSAL}

We next extend the findings of Study 2, by exploring mechanisms through which consumers can be motivated toward the disposal of their laptop computers. As identified in Study 2, retention of personal computers can be motivated by consumer beliefs, as well as product use. These act to strengthen product ownership, and increase the likelihood of product retention. As past studies suggest, however, the strength of product ownership can be weakened if consumers are provided with a justifiable reason for product replacement (Bellezza et al., 2017). In study 1, we identified two motivations for product disposal - exchanges (e.g. trade-ins), and giving to others. As such, we propose that providing consumers with reasonable rewards for product disposal such as a discount on a new product during a trade-in, or an opportunity to help others, will weaken ownership and increase product disposal. The capacity of rewards to encourage disposal, however, should diminish where the drivers of product retention are amplified. Thus in our next set of hypotheses, we explore product disposal, in the context of the drivers of product retention.

\subsection{Trade-ins}


Exchanges, such as trade-ins, are an accepted model for encouraging consumers to dispose of reusable products. Trade-ins occur in a wide range of markets including automobiles, appliances, and electronics. They primarily involve a consumer exchanging a used product for a newer, or better quality product. Trade-ins are particularly attractive to consumers where they involve durable goods, especially those with successive model generations where a consumer expects an upgrade in the future (Desai et al., 2016). Consumers use trade-ins because they reduce the personal effort required to sell used products to other individuals. They also motivate earlier replacement purchases by consumers (Ray et al., 2005; Rao et al., 2009). From an operations perspective, trade-ins are advantageous as they provide an opportunity to acquire products for reuse, and increase control over the quality of products acquired (Guide, 2000).

In individual selling scenarios, consumers tend to overvalue their possessions, especially where they have a strong sense of product ownership (Zhu et al., 2008; Srivastava and Chakravarti, 2011; Brough and Isaac, 2012). However, recent research suggests that exposure to product upgrades can weaken the bond between consumers and their possessions (Bellezza et al., 2017). Trade-ins offer a means to obtain a new product without relinquishing the residual value left in an old product (Okada, 2001; Desai et al., 2016). This provides a psychological as well as monetary gain for the consumer and can alleviate guilt about wasting resources (Bellezza et al., 2017). Frequently used products are more likely to offer continued benefit to a consumer, 
and as such, trade-ins would offer limited appeal (Okada, 2001). Consumers, however, may be more open to the trade-in of infrequently used products, given it provides an opportunity to exchange a product they are unhappy with, particularly where a return is no longer available (Okada, 2001; Desai et al., 2016). In this case, firms may be able to benefit from a consumer's willingness to exchange a recent, but unsatisfactory purchase, for a newer, better product. As identified in Study 2, frequent use can contribute to problems of product retention. With time this may further justify product retention. This suggests however, that infrequent use of a product could instead encourage product disposal, and sooner. Thus while frequent product use can strengthen product ownership, infrequent product use should lead to weaker product ownership. As such, when given an opportunity to trade-in an existing, but infrequently used product, we expect that:

H3: Consumers will accept a smaller discount to trade-in an infrequently used product, relative to a frequently used product. $^{4}$

\subsection{Trade-ins with emotional reward}

In addition to a trade-in, positive psychological gains have the potential to motivate product disposal. A consumer's negative response to disposal is driven primarily by anxieties around ownership. Threats to consumer identity from loss of a possession, and fear that a product will be misused, can limit product disposal (Brough and Isaac,

\footnotetext{
4 We use "smaller" discount (consumer wants less in return), and "larger" discount (consumer wants more in return) to indicate changes in Discount.
} 
2012; Trudel, Argo and Meng, 2016). Prior work suggests, however, that disposal can provide consumers with a positive way to disengage with their possessions. This includes moving on from the past, de-cluttering (Jacoby et al., 1977; Lastovicka and Fernandez, 2005) or framing their behavior as altruistic, by helping society through disposal (e.g. donation or recycling) (White et al., 2011; Ture, 2014; Sun and Trudel, 2017). The disposal process can shift a negative to a positive, if it offers the right compensation, or effectively alleviates consumer concerns about disposal (Lastovicka and Fernandez, 2005; Brough and Isaac, 2012).

As discussed above, trade-ins can offer both financial reward, and a product upgrade, which is attractive to many consumers. Offering an additional, 'emotional' reward with a trade-in may act to further increase the perceived benefits of trade-ins. Sellers able to identify buyers they like for example, such as a parent giving their child's old toys to a new parent, can encourage lower resale prices (Brough and Isaac, 2012; Lastovicka and Fernandez, 2005). In Study 1, an opportunity to help or give to others was a popular reason for consumers to dispose of a personal computer. The extent to which emotional rewards can motivate disposal, however, particularly where the product still has significant reuse value, is largely untested. Prior research suggests consumers are less willing to dispose of products to buyers with purely commercial intentions (Lastovicka and Fernandez, 2005; Brough and Isaac, 2012). Commercial buyers, such as manufacturers, however, may be able to employ emotional rewards during product acquisition as a way to counteract related negativity. Public zoos that 
collect used cell phones for recycling for example have had success with such approaches (Zoos Victoria, 2016). As such, trade-ins that also offer positive emotional rewards, such as promising to donate products or proceeds to charity, will increase the attraction of trade-ins. Thus, when given an opportunity to trade-in an old product, in exchange for a discount on a new product, we expect that:

H4. Consumers will accept a smaller discount to trade-in a product if they are also offered an emotional reward, relative to a trade-in with no emotional reward.

\subsection{The effects of attachment and frugality}

As outlined above, reasonable rewards for product disposal have significant scope to reduce product retention. As identified in Study 2 however, product retention will vary in strength depending on consumers’ underlying psychological characteristics. As such, in the context of the drivers of product retention, disposal rewards may have a variable effect on the willingness of consumers to accept them. More intense forms of psychological ownership then, such as higher attachment and frugality, are expected to diminish the perceived benefits of certain disposal rewards for affected consumers. While the promise of financial and/or emotional rewards may motivate many consumers, higher attachment or higher frugality may also increase resistance to them (Lastovicka and Fernandez, 2005; Brough and Isaac, 2012). 
For more attachment-prone consumers, anxieties about loss, or the implications of reuse of one's possessions by others, are triggered by product disposal. This affects attachment-prone consumers for commercial, and even altruistic methods of disposal (Brough and Isaac, 2012; Townsend, 2017). While giving to charity can allow consumers to feel better about themselves and society, for a highly attached consumer, there is still significant scope to presume misuse by the charity. As such, the more easily a consumer forms associations with products, the less likely they are to be motivated by either financial or emotional rewards associated with disposal. Low attachment consumers should be positively motivated by trade-ins, and more so if the trade-in includes an emotional reward, given their lower rates of product retention in Study 2. High attachment consumers, however, should be less motivated by either trade-ins alone or trade-ins that include an emotional reward such as giving to a charity. Thus, in exchange for a discount on a new product, we expect that:

H5. High attachment consumers will accept a larger discount to trade-in a product relative to low attachment consumers, whether or not the trade-in is associated with an emotional reward.

In study 2, we identified that frugality can also significantly increase product retention. As such, higher frugality is also proposed to diminish the benefits of disposal rewards, such that more frugal consumers should be more conspicuous about what they gain, or give away, during disposal. For high frugality consumers, forms of 
disposal reward that offer no monetary gain (i.e. the inclusion of an emotional reward) should have limited appeal. Although frugality has been linked to a consumer’s increased interest in novel ways to dispose of products, its relationship to disposal methods with non-monetary goals remains unclear (Evers et al., 2018). More frugal consumers may well be supportive of productive forms of reuse that at least minimize utility or material waste, such as low value trade-ins or recycling (Arkes, 1996; Sun and Trudel, 2017). Yet the suggestion that by disposing of products they may be directly giving away a financial benefit to others, is likely to conflict with the inherently self-focused goals of frugality (Lastovicka and Fernandez, 2005). As such, the association of an emotional reward with a trade-in opportunity in particular, such as giving the old product to charity, may invoke negative thoughts about buyer intent, such as the potential for the recipient to resell the item (Brough and Isaac, 2012). Frugal consumers are generally less concerned with how others perceive their actions, including that others might view them as "stingy” or uncharitable (Goldsmith et al., 2014; Sung and Huddleston, 2018). They can also be highly judgmental of how nonprofit organizations spend their funding, holding charities to higher standards of accountability than less frugal consumers (Townsend, 2017). As such, while we expect high frugality consumers will obtain some benefit from the inclusion of an emotional reward in trade-in opportunities, the psychological gain will be less, relative to low frugality consumers. Ideas about charities being fiscally irresponsible (Townsend, 2017), or anxiety about how recipients of their possession will use it next 
(Brough and Isaac, 2012), are expected to generate anxiety for high frugality consumers. Therefore, in exchange for a discount on a new product, we expect that:

H6a: High frugality consumers will accept a larger discount to trade-in a product relative to low frugality consumers; and

H6b: The difference between discounts among high and low frugality consumers will be greater for a trade-in associated with an emotional reward compared to a trade-in with no emotional reward.

Frugal consumers are more conscious of the monetary or utility value of their possessions, and favor independence over other consumers' concerns about social norms (Sung and Huddleston, 2018). Prior research suggests that while frugal consumers are concerned with utility maximization, they are also motivated by price or exchange promotions (Desai et al., 2016; Sung and Huddleston, 2018). As such, in contrast to the influence of attachment, frugality should at least provide scope for some consumer enthusiasm for a monetary reward from disposal. Frugal consumers are value seekers and as such, trade-ins that include a discount on a new product as well as the ability to get rid of an old (or unwanted) product should hold a level of interest for them (Okada, 2001; Desai et al., 2016). Importantly, we propose that attachment and frugality should invoke different anxieties about product ownership that can lead to different outcomes at disposal. Given the alignment of frugality with 
monetary gain, high frugality consumers should be less conflicted by the idea of trade-ins than high attachment consumers. As such, while high frugality consumers may exhibit some resistance to trade-ins in general, or trade-ins that include an emotional reward, they should still be more open to trade-ins relative to high attachment consumers. Thus, in exchange for a discount on a new product, our final hypothesis is that:

H7. High frugality consumers will accept a smaller discount to trade-in a product relative to high attachment consumers, whether or not the trade-in is associated with an emotional reward.

\subsection{Study 3}

To test the above hypotheses related to product disposal, we developed a behavioral experiment, recruiting a new sample of consumers. Use of an experiment allowed more direct control of the conditions of product ownership and product characteristics compared to Study 2, as well as presenting different types of disposal scenarios to consumers. The experiment presents each consumer with a trade-in opportunity, and measures willingness to accept a discount on a new product in return. This scenario emulates upgrade schemes already offered by some major computer retailers ${ }^{5}$. We told consumers that they had previously purchased a new laptop. Given the role of frequent use and product age in product retention identified in Study 2, we also varied

\footnotetext{
${ }^{5}$ In Study 2, when we asked consumers 'why' they had previously disposed of a computer, they overwhelmingly chose 'upgrade' (73\%) relative to other options, e.g. identity (didn’t feel like 'me’), de-cluttering, or practical reasons (moving house).
} 
the information we provided regarding how often they used their laptop, and the laptop’s age. Following this initial description, and prior to being presented with a trade-in scenario, consumers in Study 3 were asked to rate their interest in keeping the described laptop (as we did in Study 2 with reference to the subject's personal computer). After reading the scenario, we then asked them to specify a discount level they would accept to exchange their laptop for a new one. Half the sample was offered a basic trade-in, and the other half was told that in addition to the trade-in, their old laptop could be donated to a children's charity ${ }^{6}{ }^{7}$. We also measured each consumer's level of attachment and frugality at the end of the experiment.

\footnotetext{
${ }^{6}$ In Study 2, we asked consumers to rank their interest in three different disposal options - return to manufacturer, give to a charity/child-in-need, or recycle. Mean responses were: Charity $(M=3.4)$, Manufacturer $(M=1.7)$, Recycling $(M=2.5)$.

${ }^{7}$ The Charity example was designed to minimize reference to politics or personal causes. We chose 'helping children' as it was universally rewarding and involved reuse by an individual (Okada, 2001).
} 


\subsubsection{Sample and experiment design}

We recruited 450 new consumers from the same national database of consumers we used for Study 2, making sure we excluded consumers that participated in Study 2. Of the initial respondents, 68 (16\%) failed an attention check leaving 382 consumers. This failure rate is consistent with rates reported by other studies (Abbey and Meloy, 2017). Of the 382 consumers, 45\% were aged between 18 and 54; 51\% were male; $50 \%$ had at least college-level education; and 36\% had an annual income over $\$ 50,000$ AUD.

We used a 2 x 2 x 2 between-subjects design. We told consumers they had previously purchased a new laptop and that they had owned it for either 6-months (' 1 ') or 24months ('2') (Product Age), and that they were using this laptop either "rarely” ('1') or “almost always” ('2') (Frequency of Use) for the ownership period (after Okada, 2001). We first asked consumers to rate their intention to retain the laptop, using the same items for Product Retention from Study 2. We then assigned them to one of the two trade-in scenarios (Disposal Option): Trade-in ('1') or Trade-in plus Charity ('2').

[Intro text]: “Imagine you purchased a new laptop computer some time ago. You have owned this laptop computer now for [6-months/24-months]. In terms of your usage of this laptop computer to date, you have been using it [rarely/almost always]."

[Trade-in]: “In relation to this laptop computer, a friend recently made you aware

This article is protected by copyright. All rights reserved. 
that the manufacturer of your laptop computer runs a program for which they collect used laptop computers from households.”

[Trade-in plus Charity]: "In relation to this laptop computer, a friend recently made you aware that the Better Care for Foster Children Association, a registered charity operating only in Australia, runs a program where they collect used laptop computers from households in partnership with the manufacturer of your laptop computer. They then give these laptop computers to foster children living in foster care, to help them with their schoolwork." ${ }^{8}$

After reading the scenario, consumers were asked to specify a Discount (0-100\%) they would accept on a new laptop, in exchange for their current laptop. Following this, consumers completed several unrelated questions measuring Attachment Tendencies $(M=3.62, S D=0.83, \alpha=0.86)$ and Frugality $(M=4.14, S D=0.66, \alpha=0.85)$, with the same items used in Study 2. We also measured control variables for individuals’ Age, Education, Income, Gender and Number of Laptops Owned.

\subsubsection{Results}

We conducted multiple regression analysis with Discount as the dependent variable. To establish that an underlying correlation existed between retention and disposal, we initially assessed the relationship between Product Retention and Discount, and the extent to which this varied with consumers' psychological characteristics. The effect

\footnotetext{
${ }^{8}$ We avoided reference to how a manufacturer would deal with the laptops e.g. resale or recycle, to limit interference from thoughts regarding 'buyer intent' (Brough and Isaac, 2012). We also stipulated that the children's charity operated only in Australia to minimize concerns about international e-waste exports (which was raised during Study 1 as a concern).
} 
of Product Retention on Discount for Study 3 consumers was significant and positive $\left(\beta^{9}: 0.173, p=0.001^{* *}\right)$. This suggests that as Product Retention increases, the Discount accepted by consumers to dispose of their laptop also increases. In addition, the effects of Attachment Tendencies and Frugality on this relationship were consistent with the findings of Study 2, in that the effect of Product Retention on Discount was stronger at high levels of Attachment Tendencies ( $\Delta_{\text {discount at high AT: }}$ 9.14\%, $\left.p=0.003^{* *} ; \Delta_{\text {discount at low AT: }} 3.01 \%, p=0.328\right)$ and Frugality $\left(\Delta_{\text {discount at high FR: }}\right.$ $11.18 \%, p=0.001^{* *} ; \Delta_{\text {discount at low FR: }} 3.54 \%, p=0.264$ ), relative to low levels of these variables. $^{10}$

\subsubsection{Effect of disposal option on discount}

In the Study 3 main analysis, we assessed the extent to which various rewards for disposal could decrease the influence of the drivers of product retention, on Discount. First, we assessed the effect of two trade-in scenarios (Disposal Option) on the Discount needed by consumers to dispose of their laptop. The effect of Disposal Option on Discount, for all consumers and all products $(\mathrm{n}=382)$, was significant and negative $\left(\beta\right.$ : $\left.-0.214, p=0.000^{* * *}\right)$. This indicated that of the two Disposal Options, consumers would accept a significantly smaller discount for trade-ins that included an emotional reward, relative to trade-ins without emotional reward (trade-in only disposal $M_{\text {discount }}=31.81 \%$; trade-in plus charity disposal $M_{\text {discount }}=22.24 \% ; \Delta-9.57 \%$ ) (table 4). Thus, as proposed in H4, consumers were more willing to dispose of a

${ }^{9} \beta=$ standardized regression coefficient.

10 To determine 'low' and 'high' levels of continuous variables, we used the pick-a-point approach in PROCESS, which measures effects at the $16^{\text {th }}$ (low) and $84^{\text {th }}$ (high) percentile point of a variable's distribution. This follows the recommended approach of Fitzsimons (2008) and Spiller, Fitzsimons, Lynch and McLelland (2013), in which dichotomization of a continuous variable should be avoided. 
laptop if they were offered a trade-in that included an emotional reward, in this case giving a laptop to a children’s charity.

\subsubsection{Effect of disposal option $x$ frequency of use x product age on discount}

Second, to test $\mathrm{H} 3$ and further test $\mathrm{H} 4$, we assessed the effect of the interaction between Disposal Option, Frequency of Use and Product Age, on Discount. The main effect of Disposal Option on Discount was significant and negative, and while Frequency of Use and Product Age had a non-significant main effect on Discount, a significant three-way interaction existed between the three variables (effect of 3-way interaction on Discount: $\beta$ : $\left.0.302, \mathrm{R}^{2} \Delta: 0.012, \Delta p=0.02^{*}\right)$. To probe this interaction further, we inspected conditional effects at the level of Frequency of Use and Product Age in PROCESS, as provided in table 4, figures $2 \mathrm{a}$ and $2 \mathrm{~b}$, and summarized as follows.

In H3, we proposed that infrequent product use would reduce product retention, such that consumers would accept a smaller discount to trade-in an infrequently used product relative to a frequently used product. For 6-month old laptops, consumers accepted a smaller discount to dispose of laptops being infrequently used, relative to laptops being frequently used, primarily for the trade-in only disposal option (trade-in only, infrequent use: $M_{\text {discount }}=29.6 \%$; trade-in only, frequent use: $M_{\text {discount }}=37.29 \%$; $\Delta_{\text {discount }} p=0.074$ ) (figure 2a). For 6-month old laptops, where consumers were also offered an emotional reward for disposal, differences in discount due to product use were negligible. Discounts for the trade-in plus charity disposal option were, 
however, substantially lower than for trade-in only disposal. These results partly supported H3, but suggest that for 6-month old laptops, emotional reward is also a significant motivator of disposal, and perhaps more so than infrequent product use. For 24-month old laptops, consumers accepted a smaller discount to dispose of laptops being infrequently used, relative to laptops being frequently used, primarily for the trade-in plus charity disposal option (trade-in plus charity, infrequent use: $M_{\text {discount }}=18.37 \%$; trade-in plus charity, frequent use: $M_{\text {discount }}=28.04 \% ; \Delta_{\text {discount }}$ $\mathrm{p}=0.025^{*}$ ) (figure 2b). For 24-month old laptops, while differences in product use did not motivate differences in discount during trade-in only disposal, the discount levels were still lower than those for 6-month old laptops. Together, the results for both 6month old and 24-month old laptops provided partial support for H3, and point importantly to a greater willingness of consumers to dispose of 6-month old laptops because of infrequent product use, through trade-ins. The results also suggest that while infrequent product use may become less important as a motivator of disposal through simple trade-ins as products age, infrequent use will still motivate increased disposal of older products if consumers are also offered an emotional reward.

In H4, we proposed that including an emotional reward in the trade-in opportunity would also reduce product retention, and elicit smaller discounts from consumers (relative to trade-in without emotional reward). As already described, when aggregating all subjects, consumers accepted a significantly smaller discount for the trade-in plus charity disposal option, relative to the trade-in only disposal option. At 
the level of interaction between Disposal Option, Frequency of Use and Product Age, the inclusion of an emotional reward elicited a smaller discount for each product treatment condition (i.e. frequency of use x product age); this discount was significantly smaller for frequently used, 6-month old laptops $\left(\Delta_{\text {discount between disposal }}\right.$ options $\left.-17.11 \%, \mathrm{p}=0.000^{* * *}\right)$; and infrequently used, 24-month old laptops $\left(\Delta_{\text {discount }}\right.$ between disposal options $-12.03 \%, \mathrm{p}=0.005^{* *}$ ). While the inclusion of an emotional reward also decreased Discount for infrequently used, 6-month old laptops ( $\Delta_{\text {discount between }}$ disposal options $-6.96 \%)$, the change was non-significant. The inclusion of an emotional reward did not affect Discount, however, for 24-month old, frequently used laptops ( $\Delta_{\text {discount between disposal options }}-1.89 \%$ ). This result, whilst not supporting $\mathrm{H} 4$, does suggest the potential for further constraints on disposal such as effects from consumers' psychological characteristics. In particular, more frequent use of products over time, combined with consumers' psychological characteristics, may limit the benefits of an emotional reward such that it no longer has a positive effect on disposal. Overall however, H4 was supported when analyzing all subjects together, as well as for 2 of the 4 product treatment conditions.

Together with the results for $\mathrm{H} 3$ above, these findings suggest that while infrequent use and emotional reward can significantly motivate consumer product disposal, there are further potential effects arising from a consumers’ psychological characteristics. We discuss this further below. 


\section{--- FIGURES 2A, 2B HERE ---}

\subsubsection{Effect of disposal option on discount at low and high levels of attachment}

In H5, we proposed that the effect of high attachment would be to exacerbate product retention, such that consumers would need a larger discount to trade-in their laptops relative to low attachment consumers. First, we assessed the overall effect of Attachment Tendencies on the relationship between Disposal Option and Discount when aggregating all subjects (table 4, figure 3a). For low attachment consumers, the effect of including an emotional reward in the trade-in opportunity was highly beneficial ( $\left.\Delta_{\text {discount between disposal options at low AT: }}-11.74 \%, p=0.000 * * *\right)$. For high attachment consumers, however, the effect of including an emotional reward in the trade-in opportunity was significant, but substantively less so than for low attachment consumers $\left(\Delta_{\text {discount between disposal options at high AT: }}-6.63 \%, p=0.034 *\right)$. Second, for each disposal option independently, high attachment was associated with an increase in discount for both types of disposal (table 5). For the trade-in only disposal option, high attachment consumers accepted a 4.5\% larger discount than low attachment consumers. For the trade-in plus charity disposal option, high attachment consumers accepted a $9.6 \%$ larger discount than low attachment consumers $\left(\Delta \% p=0.002^{* *}\right)$. These findings suggest then, that high attachment will have a significant limiting effect on trade-ins generally, whether or not the trade-in is associated with an emotional reward. 
Third, we assessed the effect of high versus low attachment at the level of interaction between Disposal Option, Frequency of Use and Product Age (table 4 and figures 4a, 4b). For low attachment consumers, the addition of an emotional reward elicited a smaller discount for all 4 product treatment conditions, with the difference being significantly smaller for frequently used, 6-month old laptops ( $\Delta_{\text {discount between disposal }}$ options at low AT: $-17.54 \%, \mathrm{p}=0.004 * *)$; and infrequently used, 24-month old laptops ( $\Delta_{\text {discount between disposal options at low AT: }}-13.20 \%, \mathrm{p}=0.05^{*}$ ). For high attachment consumers, the addition of an emotional reward again elicited a smaller discount for all 4 product treatment conditions, however, the changes in Discount were substantively less than that found for low attachment consumers. For high attachment consumers, the difference in discount in response to the addition of an emotional reward was significant only for frequently used, 6-month old laptops $\left(\Delta_{\text {discount between disposal options at }}\right.$ high AT: $-15.69 \%, p=0.02 *)$. Furthermore, high attachment consumers accepted a 4.18\% larger discount when offered an emotional reward (relative to trade-in only), to dispose of frequently used, 24-month old laptops, although the difference was nonsignificant.

Together, these findings provide support for H5, in that the effects of high attachment on consumer disposal were to: a. limit the perceived benefits of an emotional reward in the trade-in opportunity, and b. to decrease the perceived benefits of trade-ins overall. In addition, the effects of high attachment on consumers' willingness to dispose of their laptops was most pronounced where the laptops were older (24 
months) and still being frequently used, offering further support for the findings of Study 2.

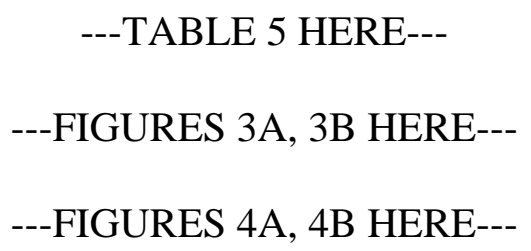

\subsubsection{Effect of disposal option on discount at low and high levels of frugality}

In H6a and H6b, we proposed that high frugality would also exacerbate product retention, leading to larger discounts relative to low frugality consumers, particularly when offered an emotional reward. First, in the overall relationship between Disposal Option and Discount (table 4, figure 3b), including an emotional reward in the tradein opportunity was highly beneficial for low frugality consumers $\left(\Delta_{\text {discount between disposal }}\right.$ options at low FR: $\left.-13.46 \%, p=0.000^{* * *}\right)$, but non-significant for high frugality consumers ( $\Delta_{\text {discount between disposal options at high FR: }}-4.34 \%, p=0.224$ ). Second, at the level of interaction between Disposal Option, Frequency of Use and Product Age (table 4 and figures 5a, 5b), for low frugality consumers, the addition of an emotional reward elicited a smaller discount for all 4 product treatment conditions. The difference was significantly smaller for frequently used, 6-month old laptops $\left(\Delta_{\text {discount between disposal }}\right.$ options at low FR: $\left.-22.12 \%, p=0.001^{* *}\right)$, and infrequently used, 24-month old laptops ( $\Delta_{\text {discount between disposal options at low FR: }}-12.83 \%, p=0.024 *$ ). For high frugality consumers however, while the addition of an emotional reward also led to a smaller discount for all 4 product treatment conditions, the decrease in discount was less than for low frugality consumers, and in all treatment conditions was non-significant. Furthermore, 
high frugality consumers accepted a 7.77\% larger discount when offered an emotional reward (relative to trade-in only), for frequently used, 24-month old laptops. These findings suggest that high frugality, like high attachment, has a significant limiting effect on the benefits of emotional reward during disposal and that these effects were greater where the laptops were older, and still being frequently used.

In H7, we proposed that high frugality consumers would accept smaller discounts for trade-ins relative to high attachment consumers, given the attraction of discounts to more frugal consumers. First, we used regression to assess the relative effects of Attachment Tendencies and Frugality on Discount when aggregating all subjects $(\mathrm{n}=382)$. While the regression was significant $\left(\mathrm{R}^{2} 0.03, \mathrm{p}=0.003^{* *}\right)$, of the main effects, only Attachment Tendencies $\left(\beta=0.169, \mathrm{p}=0.001^{* *}\right)$ was related to a significant increase in Discount, and Frugality had no effect $(\beta=0.025, \mathrm{p}=0.794)$. This suggests that when considered together, Attachment Tendencies will impose greater limits on the perceived benefits of trade-ins, and lead to larger discounts, relative to Frugality. Second, in the relationship between Disposal Option and Discount, high frugality consumers accepted a smaller discount relative to high attachment consumers for the trade-in only disposal option (high frugality $M_{\text {discount }}=30.31 \%$; high attachment $M_{\text {discount }}=33.96 \%$ ). For the trade-in plus charity disposal option, however, the difference between high frugality and high attachment consumers was negligible. To explore these results further, we inspected conditional effects in PROCESS to address the potential for combined effects on Discount from consumers' Attachment 
Tendencies and Frugality. For trade-in only disposal, consumers with high Attachment Tendencies but low Frugality, accepted higher discounts than consumers with high Frugality but low Attachment Tendencies (high attachment/low frugality: $M_{\text {discount }}=35.45 \%$; low attachment/high frugality: $\left.M_{\text {discount }}=25.74 \%\right)$. For trade-in plus charity disposal, consumers with high Attachment Tendencies but low Frugality, also accepted higher discounts than consumers with high Frugality but low Attachment Tendencies (high attachment/low frugality: $M_{\text {discount }}=26.63 \%$; low attachment/high frugality: $\left.M_{\text {discount }}=21.67 \%\right)$. Together, these results provide support for H7, suggesting that the limiting effects of high Attachment Tendencies on product disposal will be greater than the limiting effects of high Frugality, whether or not the trade-in is associated with an emotional reward.

Therefore, the main effects of high frugality were to reduce the benefits of trade-ins for consumers, relative to low frugality consumers (H6a), and particularly where the trade-in is associated with an emotional reward (H6b). The limiting effects of Frugality on product disposal, however, were lower relative to the effects of high Attachment Tendencies (H7) on product disposal.

\section{---FIGURES 5A, 5B HERE---}

\subsubsection{Effect of control variables}

We assessed control variables at the main effects level, for consumers’ Age, Income, Education, Gender and Number of Laptops Owned in regressions with Discount as the dependent variable. None of the control variables had a significant effect on discount, 
except for Number of Laptops Owned $(\beta:-0.112, p=0.04 *)$. This suggests that the discount needed by consumers during trade-ins decreases, as the number of laptops they own increases.

\subsubsection{Discussion}

Our findings show that without considering psychological characteristics, consumers were willing to accept smaller discounts to trade-in relatively new laptops (6-months old), if they were being used infrequently. The average discount needed by a consumer when trading-in an infrequently used, 6-month old laptop, was $27.56 \%$. This finding, which supported H3, has significant implications for manufacturers looking to acquire high quality products for reuse directly from consumers. Moreover, we found that including an emotional reward in the trade-in opportunity encouraged further reductions in the discount needed by consumers in the exchange. The motivating effect of including an emotional reward in the trade-in was greatest where the exchange involved: a. 6-month old laptops; or b. infrequently used, 24-month old laptops. While the inclusion of an emotional reward in the trade-in opportunity led to smaller discounts for most product treatment conditions, it provided no benefit to disposal in the case of frequently used, 24-month old laptops. These findings provided support for H4, and suggest significant scope for manufacturers to consider collection methods that also offer consumers the means to help others, or the environment.

When consumers’ psychological characteristics were considered, several findings were evident. First, supporting H5, high attachment consumers were less motivated 
by either of our trade-in options, relative to low attachment consumers, asking for larger discounts for both trade-in only, and trade-ins that included an emotional reward. Second, as proposed in H6a and H6b, high frugality consumers were less motivated by trade-ins relative to low frugality consumers, but the difference in motivation was greatest where the trade-in also included an emotional reward (with the exception of infrequently used, 24-month old laptops). Third, as proposed in H7, while high frugality in consumers led to some reduction in the attraction of trade-ins, its effect on discount was less than the effect attributed to high attachment.

In addition to these hypothesized effects, consumers with high attachment or high frugality, were least motivated by an emotional reward, where the trade-in involved a frequently used, 24-month old laptop. For these consumers, the discount level was 47\% higher than the trade-in only disposal option. This result does align with our findings in Study 2, in that frequent use of a reusable over time may act to strengthen the effects of attachment and frugality. We also noted a theme during our interviews in which consumers often mentioned anxiety about disposal of their possessions to unknown persons (see Appendix). This was largely present only when they were referencing donations to charity. Very few consumers indicated concern about returning computers to a manufacturer. Anxiety surrounding a buyer's intentions can limit disposal (Brough and Isaac, 2012). This effect may be present in our research given the product of interest (personal computers), and because concerns about data security might amplify such anxieties. The result does suggest positive support, 
however, for manufacturer involvement in programs that seek the collection of older computers (such as e-waste recycling).

Collectively, our findings have significant implications for the way in which manufacturers can market trade-in opportunities, and collect laptops from consumers. In summary, these are that: a. combining trade-ins with an emotional reward can reduce the discount needed by most consumers; b. focusing on consumers' underutilized products can reduce the discount needed to acquire relatively 'new' (6-month old) products; and c. consumers with low attachment or low frugality tendencies (e.g. minimalists, or technology focused consumers), are highly motivated by trade-ins generally, and especially trade-ins involving an emotional reward.

\section{GENERAL DISCUSSION AND IMPLICATIONS}

Our primary goal was to improve understanding of how the psychological characteristics of product ownership influence consumers' retention and disposal of reusable products. We sought to highlight aspects of psychological ownership that can act to strengthen product retention, and limit the timely disposal of products for reuse. We proposed two key counter-motivations to retention, however, and identified circumstances where psychological ownership could be leveraged to increase timely disposal of products, and lower collection costs. Across three studies, we confirmed first, that two psychological characteristics in particular would act to increase product retention (attachment and frugality). In addition, we found that frequent product use 
and frequent use over time, could intensify these effects. Second, in terms of weakening the psychological determinants of product retention, we found that certain conditions (such as infrequent product use, trade-ins and emotional reward) could improve consumer willingness to dispose of products, including products sought after by manufacturers for reuse. For older products, these conditions acted to further reduce the amount consumers expected in return for product disposal. Our findings are advantageous as they suggest methods for lowering the costs of product collection for manufacturers, both for newer products with resale value, and older products that have value only for recycling. While increased psychological tendencies reduced consumer willingness to dispose of products, which was expected, they did not prevent product disposal altogether, which is a positive finding. Overall, we found that consumers were willing to dispose of relatively new laptops (6-months old) for discounts between $27-40 \%$ with trade-in only exchanges, and between 16-20\% for exchanges that also included an emotional reward.

\subsection{Theoretical contributions}

\subsubsection{Product disposition}

In the consumer psychology literature, extant theory suggests that consumers struggle to dispose of meaningful possessions. The impact of this reluctance has been to increase prices of products consumers seek to sell, and to limit their acceptance of various disposal methods (Brough and Isaac, 2012). Missing from this literature, however, is consideration of the role of psychology in the ownership and disposal of 
reusable products, especially those with high reuse value. We found increased tendencies toward attachment and frugality to be significant factors in the desire to extend the life of personal computers. We also identified a novel interaction between psychological characteristics and frequent use, such that psychological ownership was more intense for frequently used products, the longer they were owned. Greater product use over time provides consumers with more opportunity to connect memories to products or to store information in electronic products. It may also improve a consumers' sense of product utility through increasing expectations that a product is still valuable (Okada, 2001). Regular product use over a product's lifespan could therefore reduce product disposal, rather than increase it as previously suggested in the mental accounting literature (Arkes and Blumer, 1985; Gourville and Soman, 1998; Heath and Fenema, 1996). Our findings suggest that reusable products are as prone to complex issues of psychological ownership as other product types or objects.

Our work makes four main contributions to theory regarding product disposition. First, trade-ins, and exchanges generally, can successfully weaken psychological ownership. This finding is novel in that very few studies have explored the influence of consumers’ ownership motivations during trade-ins (Bellezza et al., 2017). We also found several important variations in how effectively trade-ins could motivate disposal, depending on product use, and product age. Second, consumers can be motivated to dispose of products they are using infrequently, even relatively recent 
purchases. This suggests some alignment of our findings with the psychology of product returns. A product failure may not always lead to a product return, and consumers may retain unused products hoping to find a future, productive use for them. Once goods fall outside of a product return policy, however, the consumer has few disposal options and as such may be highly motivated to exchange products so as to offset a loss (Okada, 2001). Third, we established a significant role for emotional reward in motivating the disposal of products with high reuse value, which has not to our knowledge been empirically tested before. Finally, the psychology of attachment and frugality are complex - their effects clearly vary by type of disposal reward. Both high attachment and high frugality limited the benefits of giving to charity for consumers, yet other 'helping' incentives, such as saving the environment or other types of reuse, could produce different (and improved) results.

\subsubsection{Product acquisition}

Prior research in product acquisition has largely assumed that economics drive consumer decision-making during product disposal. The assumption has been that consumers are rational decision-makers, and affected only by market-defined product value during disposal (Zhu et al., 2008; Desai et al., 2016). As our research highlights, consumers often use a non-economic rationale for making the decision about when to dispose of a product, and its worth.

For manufacturers, a key finding of our research was a greater willingness of consumers to trade-in their underutilized products. Such products are attractive for 
reuse as they have less 'wear and tear' and can attract higher resale prices (Guide and Van Wassenhove, 2001; Galbreth and Blackburn, 2010). We identified a discount level of $29.6 \%$ in exchange for consumers' 'near-new' (6-month old) products, if they were rarely being used. This represents a potentially lucrative product for product acquisition efforts to target. Psychologically, consumers may have numerous reasons for the under-utilization of products. Products bought online may be disappointing once they physically arrive, or a product is given as a gift, but never enjoyed by the consumer. As Bellezza et al. (2017) found, consumers can quickly grow bored with a new purchase, preferring a later product model instead. Guilt around waste, or optimism about still using the product, can prevent consumers from returning products under return policies or within the return period. Such consumers, however, may well be highly receptive to the replacement or upgrade value of a trade-in.

Finally, the positive response of consumers to trade-ins that include an emotional reward suggests several avenues for further research. For one, including such rewards in appeals for products could reduce the costs to collect older products. Emotional rewards could also be used to increase in-store sales. H\&M for example asks consumers to drop-off their unwanted clothing at retail outlets, so it can be recycled, as well as offering vouchers to spend on new products. As others have found, meaningful reuse, such as selling to people we like, or giving to charities is a powerful motivator of disposal (Lastovicka and Fernandez, 2005; Brough and Isaac, 2012; Ture, 2014). Co-sponsorship of collection by charities or social programs may 
lead to substantially lower rebates for trade-ins. Overall, our findings contribute to research in product acquisition by identifying an array of options for acquiring products that fall outside of "returns". While product returns are the "low hanging fruit” of product acquisition, they are only a fraction of all products available for acquisition from consumers.

\subsection{Managerial implications}

We searched current trade-in prices on a major manufacturer's website, for a 6-month old current model laptop computer. The manufacturer offered an average rebate of $50 \%$ for the product, for use on any of the manufacturer's products. Thus the discounts identified in our experiments (16-41\%) compare very favorably with discounts already offered by manufacturers in practice. This suggests that manufacturers have significant scope to reduce the amount they normally offer consumers, to acquire high quality products. Our findings also suggest significant potential to tailor their approaches via product appeals that tap into consumer psychological characteristics. Appealing to consumers’ guilt around unused utility, for example, could entice higher quality trade-ins. Product take-back programs rarely offer rewards aimed at the psychology of consumers, using only prices set by product class, and little in the way of a motivational narrative, such as the social or environmental benefits of reuse. There is reason to expect that manufacturers could significantly improve product acquisition by marketing the positive benefits of reuse to consumers. Small product drop-offs at public events, in-store drop-offs, or 
initiatives advertising waste reduction or price promotions, could substantially improve the effectiveness of product acquisition.

For products not suitable for reuse but still in need of collection, our findings provide several opportunities for manufacturers. Manufacturers increasingly need to remove older products from circulation, such as obsolete products or because of regulations (Atasu and Souza, 2013; Esenduran et al., 2016). Collection of low value products, however, is difficult and expensive (Gregory and Kirchain, 2008). Significant scope exists for manufacturers to work with specialist organizations that can assist with collection, or help decommission and recycle difficult-to-obtain products. Products that are of value to recyclers could be targeted through take-back campaigns that offer tax breaks such as rebates for old fridges, or 'cash-for-clunkers' programs.

Manufacturers could lower their costs for collection by working with not-for-profits, recyclers or governments to incentivize consumers to properly recycle hazardous products. Several countries already subsidize recycler-manufacturer partnerships as a way to lower the costs of e-waste collection. Our research suggests ways to improve the effectiveness of such initiatives by tailoring them to consumers’ psychological motives for product disposal. 


\section{CONCLUSIONS AND FURTHER RESEARCH}

We contribute to a growing, but still nascent line of research that incorporates consumers’ non-economic psychology in product disposal decisions (Okada, 2001; Brough and Isaac, 2012; Desai et al., 2016; Bellezza et al., 2017). Our specific contribution is to consider the role of psychological characteristics in product ownership, and how it may be leveraged to increase product disposal. Our findings challenge existing assumptions that consumer replacement decisions are always economic.

Prior scholarship on product acquisition offers limited insight as to the real role of consumer's psychological characteristics in product disposal. This literature does not explore either the psychology of product ownership, nor products that fall outside of return policies. In fact, almost no behavioral-focused research exists in this domain, other than studies regarding the purchase of remanufactured products (Abbey et al., 2015a; 2015b). Given this, we drew from theory outside of operations management, and applied a consumer-behavior lens to an acquisition problem. While our sample was limited to a population resident in Australia, our consumers were from a diverse range of nationalities and a demographic commensurate with developed economies. We chose not to sample more broadly to avoid geographic variations in the understanding of terms such as "disposal”, or expectations regarding the charity we described. Our use of three separate studies, with three separate groups of consumers, however, leads us to expect generalizability of our results to other countries. A further 
limitation is that our experiment relied on an artificial setting such that we simulated ownership of a consumer possession (rather than true product ownership) and consumers' behavior may vary slightly for their 'lived' possessions.

There are several opportunities to extend our research. First, additional studies could replicate our conditions for a shorter, 90-day product ownership period. Second, we limited our assessment of waste-related psychologies to frugality. Waste aversion is a multi-faceted concept that has implications not just for frugality, but also beliefs around environmental harm (Haws et al., 2012). Frugality itself is a complex concept that has not previously been addressed in studies relevant to product acquisition and it may have other applications. Consumer behavior is a rich theoretical palette to draw from, and many other aspects of consumers’ psychological characteristics are applicable to used product disposal (e.g. identity, materialism, minimalism, environmentalism). Recent studies that apply a consumer behavior lens to problems of disposal or remanufacturing have identified significant and novel insights (e.g. Abbey et al., 2015a; Sun and Trudel, 2017; Bellezza et al., 2017). In Bellezza et al.’s (2017) study for example, consumers deliberately damaged still functioning products in order to justify an upgrade to a new product they wanted, to avoid feeling wasteful. Consumers may also be more eager to purchase remanufactured products if it means they can replace a faulty, damaged or unwanted product sooner or for a lower price. Our findings add to this body of work by further highlighting the potential of 
consumer behavior to assist with untangling complex problems of product disposal, and its implications for product acquisition. 


\section{REFERENCES}

Abbey, J. D., Meloy, M. G., Guide, V. D. R. and Atalay, S. 2015a. Remanufactured Products in Closed-Loop Supply Chains for Consumer Goods. Production and Operations Management, 24(3), 488-503.

Abbey, J. D., Meloy, M. G., Blackburn, J. and Guide, V. D. R. 2015b. Consumer Markets for Remanufactured and Refurbished Products. California Management Review, 57(4), 26-42.

Abbey, J.D. and Meloy, M.G. 2017. Attention by design: Using attention checks to detect inattentive respondents and improve data quality. Journal of Operations Management, 53-56, 63-70.

Arkes, H. R. 1996. The psychology of waste. Journal of Behavioral Decision Making, 9(3), 213-224.

Arkes, H. R., and Blumer, C. 1985. The psychology of sunk costs. Organizational Behavior and Human Decision Processes, 35(1): 124-140.

Atasu, A. and Souza, G. C. 2013. How Does Product Recovery Affect Quality Choice? Production and Operations Management, 22(4), 991-1010.

Atasu, A. and Van Wassenhove, L. N. 2012. An Operations Perspective on Product Take-Back Legislation for E-Waste: Theory, Practice, and Research Needs. Production and Operations Management, 21(3), 407-422.

Atasu, A., Guide, V. D. R. and Van Wassenhove, L. N. 2010. So what if remanufacturing cannibalizes my new product sales? California Management Review, 52(2), 56-76. 
Atasu, A., Toktay, L. B. and Van Wassenhove, L. N. 2013. How collection cost structure drives a manufacturers reverse channel choice. Production and Operations Management, 22(5), 1089-1102.

Babbitt, C. W., Williams, E., and Kahhat, R. 2011. Institutional disposition and management of end-of-life electronics. Environmental Science and Technology, 45(12): 5366-5372.

Belk, R. W. 1988. Possessions and the extended self. Journal of Consumer Research, 15(2): 139-168.

Bellezza, S., Ackerman, J. M. and Gino, F. 2017. "Be careless with that!" Availability of product upgrades increases cavalier behavior toward possessions. Journal of Marketing Research, 54(5), 768-784.

Blackburn, J. D., Guide, V. D. R., Souza, G. C. and Van Wassenhove, L. N. 2004. Reverse supply chains for commercial returns. California Management Review, 46(2), 6-22.

Bolton, L. E. and Alba, J. W. 2012. When less is more: Consumer aversion to unused utility. Journal of Consumer Psychology, 22(3): 369-383.

Brough, A and Isaac, M. 2010. When products are valued more but sold for less: the impact of waste aversion on disposal behavior. In NA-Advances in Consumer Research, M. C. Campbell, J. Inman and R. Pieters (eds). Duluth, MN: Association for consumer research, pp.484-485. 
Brough, A. R. and Isaac, M. S. 2012. Finding a home for products we love: how buyer usage intent affects the pricing of used goods. Journal of Marketing, 76(4): 7891.

Chandler, J. and Schwarz, N. 2010. Use does not wear ragged the fabric of friendship: Thinking of objects as alive makes people less willing to replace them. Journal of Consumer Psychology, 20(2), 138-145.

Clottey, T., Benton, W. C., and Srivastava, R. 2012. Forecasting product returns for remanufacturing operations. Decision Sciences, 43(4): 589-614.

Coulter, R. A. and Ligas, M. 2003. To retain or to relinquish: Exploring the disposition practices of packrats and purgers. Advances in Consumer Research, 30(30), 38-43.

Curasi, C. F., Price, L. L. and Arnould, E. J. 2004. How individuals' cherished possessions become families' inalienable wealth. Journal of Consumer Research, 31(3), 609-622.

Desai, P. S., Purohit, D. and Zhou, B. 2016. The strategic role of exchange promotions. Marketing Science, 35(1), 93-112.

Dommer, S. L. and Swaminathan, V. 2013. Explaining the endowment effect through ownership: the role of identity, gender, and self-threat. Journal of Consumer Research, 39(5): 1034-1050.

Environmental Protection Agency (EPA), 2011. Electronics waste management in the United States through 2009. (EPA 530-R-11-002). 
Esenduran, G., Kemahlioglu-Ziya, E., and Swaminathan, J. M. 2016. Take-back legislation: consequences for remanufacturing and environment. Decision Sciences, 47(2), 219-256.

Evers, U., Gruner, R. L., Sneddon, J., and Lee, J. A. 2018. Exploring materialism and frugality in determining product end-use consumption behaviors. Psychology and Marketing, 35(12), 948-956.

Ferguson, M. E. and Toktay, L. B. 2006. The effect of competition on recovery strategies, Production and Operations Management, 15(3), 351-368.

Ferguson, M., Guide, V. D. R. and Souza, G. C. 2006. Supply chain coordination for false failure returns. Manufacturing and Service Operations Management, 8(4), 376393.

Fitzsimons, G. J. (2008). Death to dichotomizing. Journal of Consumer Research, 35(1), 5-8.

Fornell, C. and Larcker, D. F. 1981. Evaluating structural equation models with unobservable variables and measurement error. Journal of Marketing Research, 18(1): 39-50.

Galbreth, M. R. and Blackburn, J. D. 2010. Optimal acquisition quantities in remanufacturing with condition uncertainty. Production and Operations Management, 19(1), 61-69.

Gioia, D. A., Corley, K. G., and Hamilton, A. L. 2012. Seeking qualitative rigor in inductive research: Notes on the Gioia methodology. Organizational Research Methods, 16: 15-31. 
Goldsmith, R. E., Flynn, L. R., and Clark, R. A. 2014. The etiology of the frugal consumer. Journal of Retailing and Consumer Services, 21(2), 175-184.

Gourville, J. T., and Soman, D. 1998. Payment depreciation: The behavioral effects of temporally separating payments from consumption. Journal of Consumer Research, 25(2): 160-174.

Gregory, J. R. and Kirchain, R. E. 2008. A framework for evaluating the economic performance of recycling systems: A case study of worth American electronics recycling systems. Environmental Science and Technology, 42(18): 6800-6808. Griffis, S. E., Rao, S., Goldsby, T. J. and Niranjan, T. T. 2012. The customer consequences of returns in online retailing: An empirical analysis. Journal of Operations Management, 30(4), 282-294.

Guide, V. D. R. and Jayaraman, V. 2000. Product acquisition management: Current industry practice and a proposed framework. International Journal of Production Research, 38(16), 3779-3800.

Guide, V. D. R. and Van Wassenhove, L. N. 2001. Managing product returns for remanufacturing. Production and Operations Management, 10(2), 142-155.

Guide, V. D. R. 2000. Production planning and control for remanufacturing: Industry practice and research needs. Journal of Operations Management, 18(4), 467-483.

Guide, V. D. R., Souza, G. C., Van Wassenhove, L. N. and Blackburn, J. D. 2006. Time value of commercial product returns. Management Science, 52(8), 1200-1214. 
Hahler, S. and Fleischmann, M. 2017. Strategic grading in the product acquisition process of a reverse supply chain, Production and Operations Management, 26(8), 1498-1511.

Haws, K. L., Naylor, R. W., Coulter, R. A. and Bearden, W. O. 2012. Keeping it all without being buried alive: Understanding product retention tendency. Journal of Consumer Psychology, 22(2): 224-236.

Heath, C. and Fennema, M. G. 1996. Mental depreciation and marginal decision making. Organizational Behavior and Human Decision Processes, 68(2), 95-108. Ho, T. H., Png, I. P. L., and Reza, S. 2018. Sunk cost fallacy in driving the world's costliest cars. Management Science, 64(4): 1761-1778.

Jacoby, J., Berning, C. K. and Dietvorst, T. F. 1977. What about disposition? Journal of Marketing, 41(2): 22-28.

Kahneman, D., Knetsch, J. L. and Thaler, R. H. 1990. Experimental tests of the endowment effect and the coase theorem. Journal of Political Economy, 98(6): 13251348.

Kim, J., Rao, R. S., Kim, K. and Rao, A. R. 2011. More or less: a model and empirical evidence on preferences for under- and overpayment in trade-in transactions. Journal of Marketing Research, 48(1), 157-171.

Klausner, M. and Hendrickson, C. T. 2000. Reverse-logistics strategy for product take-back, Interfaces, 30(3), 156-165.

Kleine, S.S. and Baker, S.M. 2004. An integrative review of material possession attachment. Academy of Marketing Science Review, 1(1), 1-35. 
Kleine, S. S., Kleine, R. E. and Allen, C. T. 1995. How is a possession "me" or "not me"? Characterizing types and an antecedent of material possession attachment. Journal of Consumer Research, 22(3), 327-343.

Lam, C. W., Lim, S. R. and Schoenung, J. M. 2013. Linking material flow analysis with environmental impact potential dynamic technology transition effects on projected e-waste in the United States. Journal of Industrial Ecology, 17(2), 299-309. Lastovicka, J. L. and Fernandez, K. V. 2005. Three paths to disposition: The movement of meaningful possessions to strangers. Journal of Consumer Research, 31(4): 813-823.

Lastovicka, J. L. and Sirianni, N. J. 2011. Truly, madly, deeply: consumers in the throes of material possession love. Journal of Consumer Research, 38(2): 323-342. Lastovicka, J. L., Bettencourt, L. A., Hughner, R. S. and Kuntze, R. J. 1999. Lifestyle of the tight and frugal: Theory and measurement. Journal of Consumer Research, 26(1): 85-98.

Norton, M. I., Mochon, D. and Ariely, D. 2012. The IKEA effect: When labor leads to love. Journal of Consumer Psychology, 22(3), 453-460.

Nunnally, J.C. and Bernstein, I.H. 1994. Psychometric Theory. McGraw-Hill, New York.

Okada, E. M. 2001. Trade-ins, mental accounting, and product replacement decisions. Journal of Consumer Research, 27(4): 433-446.

Ovchinnikov, A. 2011. Revenue and cost management for remanufactured products. Production and Operations Management, 20(6), 824-840. 
Palmer, B. 2009. Clutter Busting: letting go of whats holding you back. New World Library, Novato, California.

Peck, J. and Shu, S. B. 2009. The effect of mere touch on perceived ownership. Journal of Consumer Research, 36(3), 434-447.

Phillips, B. J. and Sego, T. 2011. The role of identity in disposal: Lessons from mothers' disposal of children's possessions. Marketing Theory, 11(4), 435-454. Pratt, M., Rockmann, K. and Kaufmann, J. 2006. Constructing professional identity: The role of work and identity learning cycles in the customization of identity among medical residents. Academy of Management Journal, 49:2, 235-262.

Rao, R. S., Narasimhan, O. and John, G. 2009. Understanding the role of trade-ins in durable goods markets: theory and evidence. Marketing Science, 28(5), 950-967.

Ray, S., Boyaci, T. and Aras, N. 2005. Optimal prices and trade-in rebates for durable, remanufacturable products, Manufacturing and Service Operations Management, 7(3), 208-228.

Sabbaghi, M., Esmaeilian, B., Mashhadi, A. R., Behdad, S. and Cade, W. 2015. An investigation of used electronics return flows: A data-driven approach to capture and predict consumers storage and utilization behavior. Waste Management, 36, 305-315. Saphores, J., Nixon, H., Ogunseitan, O. and Shapiro, A. 2009. How much e-waste is there in US basements and attics? Results from a national survey. Journal of Environmental Management, 90(11), 3322-3331. 
Savaskan, R. C., Bhattacharya, S. and Van Wassenhove, L. N. 2004. Closed-loop supply chain models with product remanufacturing. Management Science, 50(2), 239252.

Seitz, M. A. 2007. A critical assessment of motives for product recovery: the case of engine remanufacturing. Journal of Cleaner Production, 15(11-12), 1147-1157.

Shang, G., Pekgun, P., Ferguson, M. and Galbreth, M. 2017. How much do online consumers really value free product returns? Evidence from eBay. Journal of Operations Management, 53-56, 45-62.

Shih, C. F., and Venkatesh, A. 2004. Beyond adoption: Development and application of a use-diffusion model. Journal of Marketing, 68(1), 59-72.

Souza, G. C. 2013. Closed-loop supply chains: a critical review, and future research. Decision Sciences, 44(1), 7-38.

Spiller, S. A., Fitzsimons, G. J., Lynch, J. G., and McClelland, G. H. 2013. Spotlights, floodlights, and the magic number zero: simple effects tests in moderated regression. Journal of Marketing Research, 50(2), 277-288.

Srivastava, J. and Chakravarti, D. 2011. Price Presentation Effects in Purchases Involving Trade-Ins. Journal of Marketing Research, 48(5), 910-919.

Sun, M. and Trudel, R. 2017. The Effect of Recycling Versus Trashing on Consumption: Theory and Experimental Evidence. Journal of Marketing Research, 54(2), 293-305.

Sung, E., and Huddleston, P. 2018. Department vs discount retail store patronage: effects of self-image congruence. Journal of Consumer Marketing, 35(1), 64-78. 
Thaler, R. H. 1999. Mental accounting matters. Journal of Behavioral Decision Making, 12(3): 183-206.

Townsend, C. 2017. The price of beauty: differential effects of design elements with and without cost implications in nonprofit donor solicitations. Journal of Consumer Research, 44(4), 794-815.

Trudel, R., Argo, J. J. and Meng, M. D. 2016. The recycled self: consumers disposal decisions of identity-linked products. Journal of Consumer Research, 43(2), 246-264. Ture, M. 2014. Value-in-disposition: exploring how consumers derive value from disposition of possessions. Marketing Theory, 14(1), 53-72. United Nations Environment Programme (UNEP) 2015. Waste crime - waste risks: gaps in meeting the global waste challenge. Ed: Rucevska I., et al. United Nations Environment Programme and GRID-Arendal report, Nairobi and Arendal. White, K., MacDonnell, R., and Dahl, D. W. 2011. Its the mind-set that matters: the role of construal level and message framing in influencing consumer efficacy and conservation behaviors. Journal of Marketing Research, 48(3): 472-485.

Zhu, R., Chen, X. L., and Dasgupta, S. 2008. Can trade-ins hurt you? Exploring the effect of a trade-in on consumers' willingness to pay for a new product. Journal of Marketing Research, 45(2): 159-170.

Zoos Victoria. 2016. “They’re calling on you”, www.zoo.org.au/news/theyre-callingon-you. Cell Phone Recycling Campaign, Melbourne, Australia. 


\section{FIGURES AND TABLES}

Figure 1. Overview of studies

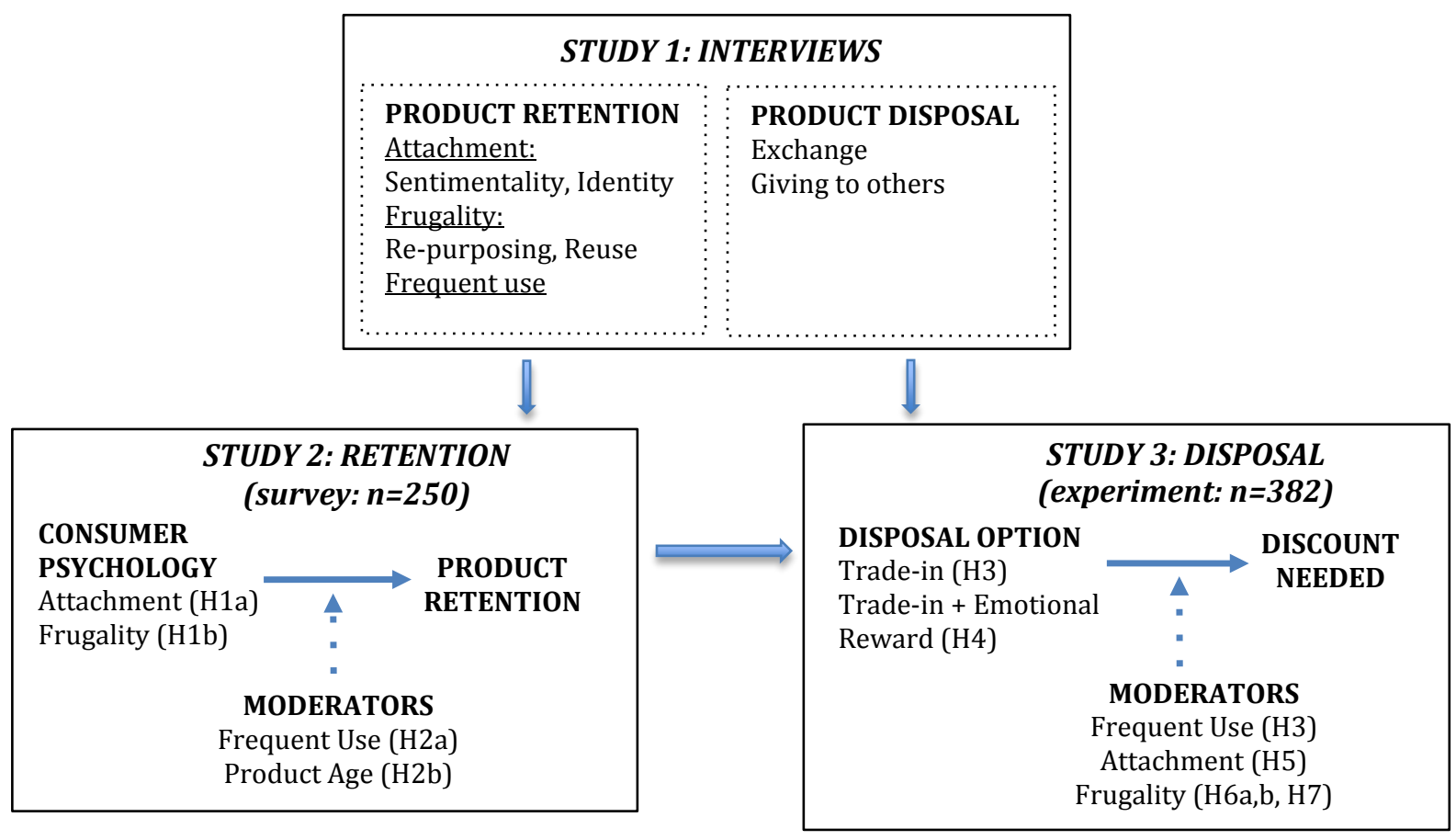

This article is protected by copyright. All rights reserved. 


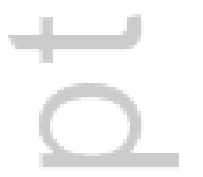

This article is protected by copyright. All rights reserved. 
Table 1. Themes and illustrative quotes from consumer interviews (Study 1)

Product retention (macro-order theme 1)

Attachment
Sentimentality
and Identity
(17 excerpts)

- I look at my iPad more as a mate than just like a simple electrical device.

- I would keep it as a showpiece - as a museum piece. If it's completely gone, maybe I would just keep it as a showpiece. Some sentiments attached still.

- A long time back we got a Walkman from Sony, and I still have that Walkman; it doesn't work, but I won't throw it away - I'll still keep it. I said, 'should I throw it away?' No, no, it goes back, so I'm still keeping it.

Overvaluing

- I was given my i-pod for free and it is probably worth about \$8 on e-bay now. But I

(5 excerpts) would never accept that little amount of money. I think it is worth much more than that.

\section{Frugality}

Repurposing

(26 excerpts)

- We hook up the computer to the TV, so whatever songs or movies are stored on that it's become more of a storage space.

- If the laptop that I'm currently using is broken then I could use that (the old one) as the emergency.

Reuse - I'm a bit sensitive about throwing away this stuff if I know that they cause some

(14 excerpts) damage to the environment.

- I don't like just throwing things away that can still work.

Just-in-case $\quad$ - It was easier to just keep it under my desk. It's there in case I ever do need it. It's kind (8 excerpts) of a safety blanket. I'm a bit of a hoarder.

- If they're not broken you just keep them in case your new one breaks.

- I don't need to use it now but I might need it later ... they're not taking up much room at the moment. It'll probably stay until I can find a reason to get rid of it.

Frequent use $\quad$ - I use it daily ... emails, researching for units that I'm doing, researching for products

(16 excerpts) that I'm buying, reading the news online... I use it as a huge research tool, basically.

- These days, I can tell you, almost everywhere I go - and I'm travelling a lot - it has to be with me, especially the iPad ... even when I go to bed, I go to bed with my iPad.

- It's my life, you know. My laptop does everything for me. I use it primarily for educational purposes ... or certainly for entertainment purposes. We link it to our TV and watch movies and all those kinds of stuff.

\section{Product Disposal (macro-order theme 2)}

Helping others - I think charity could be a good motivator to actually push you out of the door. It would (22 excerpts) be like doing it for a kid who's got cancer and is sixteen years old or something, as opposed to hanging on to the 'what if'; like 'what if I do need some random program?' - I didn’t feel like selling my computer. I didn’t want to make money out of it, but I thought I wanted it to go to good use, so I thought much better why not a junior college student.

- You won’t get much money for selling it. It would just be like two hundred dollars. So it's better to donate.

- I gave my laptops to my sisters ... while they're no use to me and I've upgraded, they're too good to throw away.

Exchange - If it works then I'll try to sell it through Gumtree or something like that.

(14 excerpts) - When I got this computer I just sold that one...it was still working.

- I will exchange it with the suppliers to get a new one.

- That's what I did with my first computer. It was very slow, it wasn't working, so I gave it to the computer shop and they gave me a discount on my new system.

- I swapped one of my earlier desktops for another computer. 


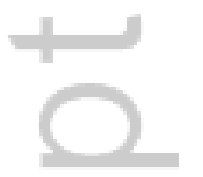

This article is protected by copyright. All rights reserved. 
Table 2. Regression results (Study 2) (H1a, H1b)

\begin{tabular}{|lll|}
\hline \hline & \multicolumn{2}{c|}{ Standardized Coefficients ${ }^{a}$} \\
\hline Intercept & $3.513^{* * *}$ & $1.582^{*}$ \\
Age & 0.085 & 0.102 \\
Income & 0.005 & 0.003 \\
Education & $-0.152^{*}$ & $-0.153^{*}$ \\
Gender & $0.138^{*}$ & 0.083 \\
How many computers owned & -0.020 & 0.040 \\
Attachment (AT) & & $0.185^{* *}$ \\
Frugality (FR) & & $0.183^{* *}$ \\
Frequency of use (F) & & $-0.151^{*}$ \\
Product age (PA) & & -0.077 \\
Adj. $R^{2}$ & $0.057^{*}$ & $0.142^{* * *}$ \\
F-value (sig. F change) & $2.923\left(^{*}\right)$ & $4.419\left(^{* * *}\right)$ \\
\hline
\end{tabular}

Table 3. The effects of attachment and frugality on product retention, by frequency of use and product age (H2a, H2b) (Study 2)

\begin{tabular}{|rcc|cc|cc|}
\hline \hline \multicolumn{8}{c|}{ Unstandardized coefficients } \\
\hline Product age $^{a}$ & \multicolumn{2}{c|}{ 6-months } & \multicolumn{2}{c|}{ 24-months } & \multicolumn{2}{c|}{ 48-months } \\
Frency of use $^{a}$ & $\mathrm{~F}$ & $\mathrm{O}$ & $\mathrm{F}$ & $\mathrm{O}$ & $\mathrm{F}$ & $\mathrm{O}$ \\
\hline${\text { Attachment } \rightarrow \text { Product retention }^{b}}^{b}$ & 0.155 & 0.150 & $0.243^{* *}$ & 0.136 & $0.360^{* *}$ & 0.117 \\
Frugality $\rightarrow$ Product retention $^{b}$ & 0.111 & 0.218 & $0.267 * *$ & 0.223 & $0.475^{* *}$ & 0.230 \\
\hline
\end{tabular}

${ }^{a}$ Moderator variable. ${ }^{b}$ Dependent variable. $\mathrm{F}=$ Frequent use (1), $\mathrm{O}=$ Other use (0). Effect of Product Age is assessed at 6, 24 and 48-months, which are the $16^{\text {th }}, 50^{\text {th }}$ and $84^{\text {th }}$ percentile points of the variable. ${ }^{* * *} p<0.001,{ }^{* *} p<0.01,{ }^{*} p<0.05$. 
Table 4. Change in discount between disposal options, by frequency of use and product age, and psychological characteristics (Study 3)

\begin{tabular}{|c|c|c|c|c|c|c|c|c|c|c|c|c|c|c|c|}
\hline \multirow{2}{*}{$\begin{array}{c}\text { Product } \\
\text { Treatment }\end{array}$} & \multirow{2}{*}{\multicolumn{3}{|c|}{ Consumers $(n=382)$}} & \multicolumn{6}{|c|}{ Attachment Tendencies (AT) } & \multicolumn{6}{|c|}{ Frugality (FR) } \\
\hline & & & & \multicolumn{3}{|c|}{ Low AT } & \multicolumn{3}{|c|}{ High AT } & \multicolumn{3}{|c|}{ Low FR } & \multicolumn{3}{|c|}{ High FR } \\
\hline $6 \mathrm{~m}-\mathrm{IF}$ & $29.60(48)^{2}$ & $22.64(45)$ & -6.96 & 27.56 & 16.01 & -11.55 & 32.31 & 27.30 & -5.01 & 26.52 & 20.64 & -5.88 & 32.69 & 26.72 & -5.97 \\
\hline $24 \mathrm{~m}-\mathrm{IF}$ & 30.40 (47) & 18.37 (49) & $-12.03^{* *}$ & 30.89 & 17.69 & $-13.20 *$ & 29.95 & 19.06 & -10.89 & 31.69 & 18.86 & $-12.83^{*}$ & 28.3 & 17.43 & -10.87 \\
\hline $24 \mathrm{~m}-\mathrm{F}$ & 29.96 (49) & $28.04(47)$ & -1.89 & 26.36 & 20.05 & -6.31 & 33.06 & 37.24 & 4.18 & 32.09 & 20.94 & -11.15 & 27.27 & 35.04 & 7.77 \\
\hline
\end{tabular}

${ }^{1} \Delta$ in Discount (0-100\%) between two disposal options. ${ }^{2}$ number $(n)$ of total consumers in the product treatment condition.

${ }^{* * *} p<0.001,{ }^{* *} p<0.01,{ }^{*} p<0.05$. Disposal Option: T=Trade-in; TC=Trade-in plus Charity; Product Age: 6-months, 24-months; Frequency of Use: IF=Infrequent use, F=Frequent use. 
Figure 2a. The effects of Disposal Option and Frequency of Use on Discount for 6month old laptops (H3, H4)

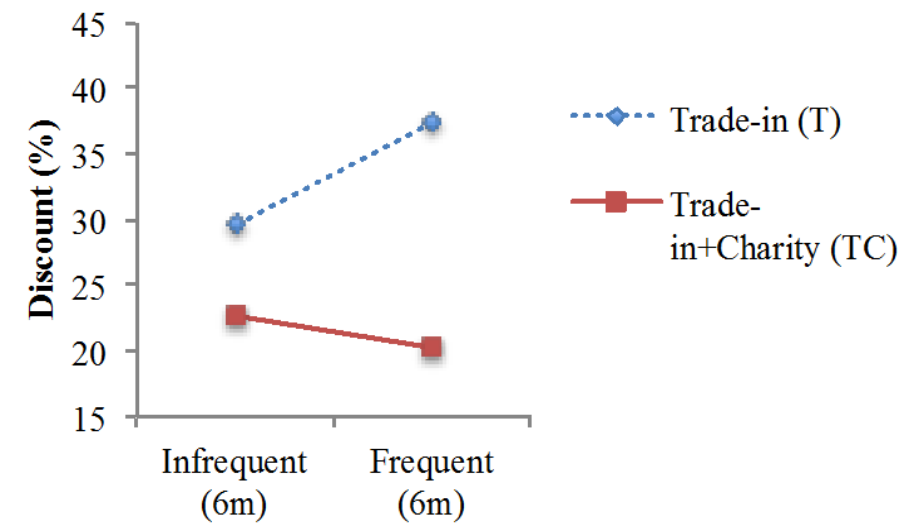

* Disposal Option: Trade-in; Trade-in plus Charity. Frequency of Use: Infrequent use; Frequent use. Product Age: 6m=6-months.

Figure 2b. The effects of Disposal Option and Frequency of Use on Discount for 24month old laptops (H3, H4)

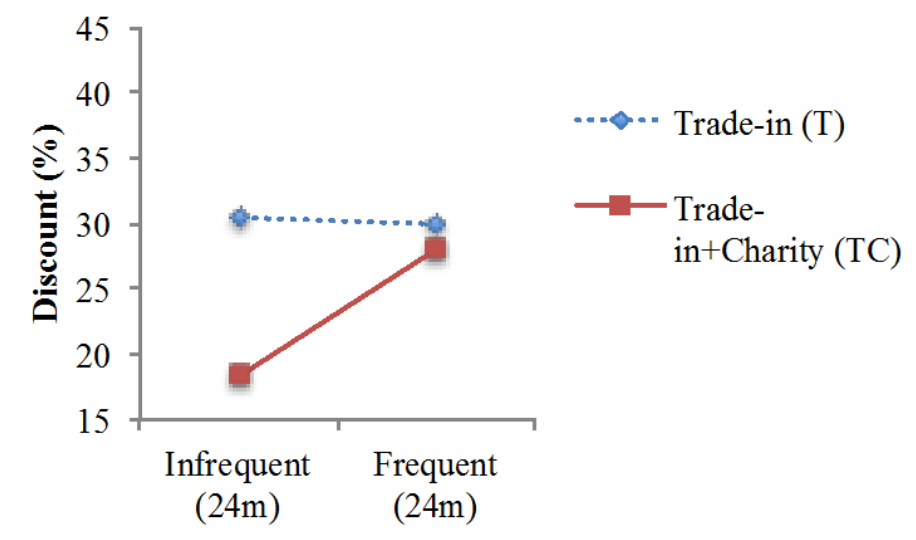

* Disposal Option: Trade-in; Trade-in plus Charity. Frequency of Use: Infrequent use; Frequent use. Product Age: $24 \mathrm{~m}=24$-months. 
Figure 3a. The effects of Disposal Option on Discount, at low and high Attachment Tendencies (H5, H7)

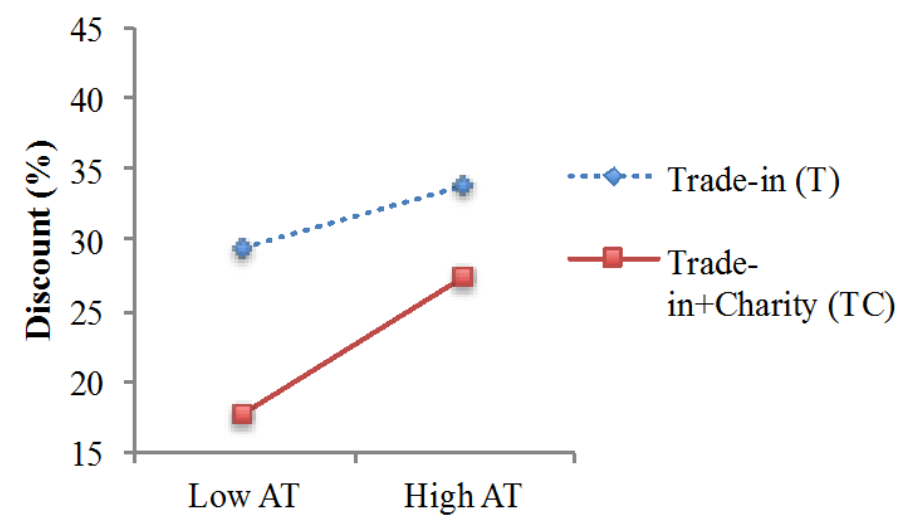

* Disposal Option: Trade-in; Trade-in plus Charity. AT=Attachment Tendencies.

Figure 3b. The effects of Disposal Option on Discount, at low and high Frugality (H6a, H6b, H7)

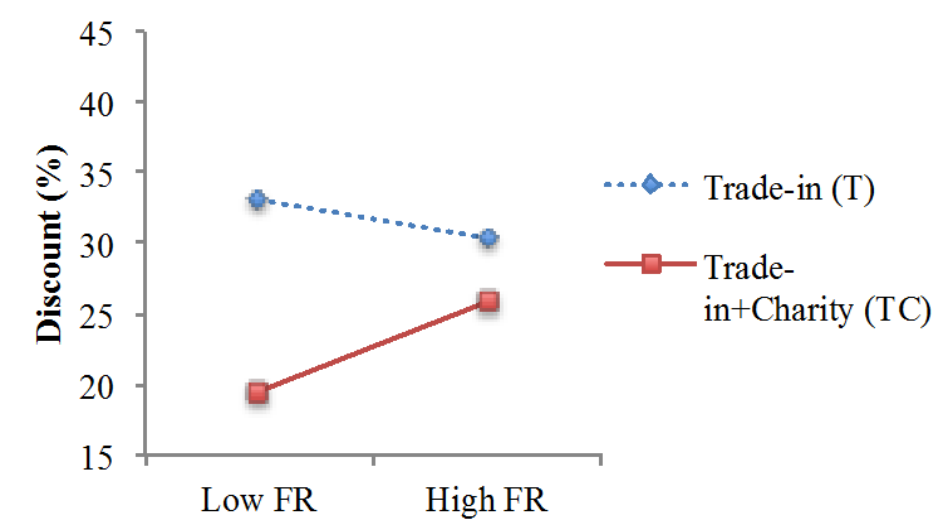

* Disposal Option: Trade-in; Trade-in plus Charity. FR=Frugality.

Table 5. Change in Discount for each Disposal Option, from low to high Attachment Tendencies and Frugality (H7) (Study 3)

\begin{tabular}{|c|c|c|c|c|}
\hline & \multicolumn{2}{|c|}{${ }^{1} \triangle \%$ from Low AT to High $A T$} & \multicolumn{2}{|c|}{${ }^{1} \triangle \%$ from Low FR to High FR } \\
\hline & Trade-in & Trade-in+Charity & Trade-in & Trade-in+ Charity \\
\hline All products & 4.50 & $9.60 * *$ & -2.68 & $6.44^{*}$ \\
\hline
\end{tabular}

${ }^{*} p<0.05 .{ }^{1} \Delta$ in Discount (0-100\%). Disposal Option: Trade-in; Trade-in plus Charity. AT=Attachment Tendencies; FR=Frugality. 


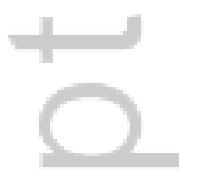

This article is protected by copyright. All rights reserved. 
Figure 4a. The effects of Disposal Option and Frequency of Use on Discount, at low and high Attachment Tendencies, for 6-month old laptops (H5)

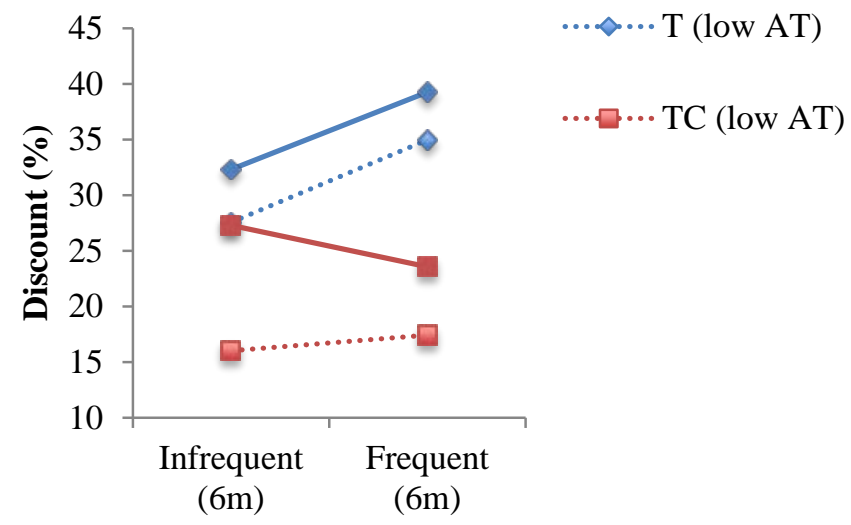

* Disposal Option: T=Trade-in; TC=Trade-in plus Charity. Frequency of Use: Infrequent use; Frequent use. AT=Attachment Tendencies. Product Age: 6m=6-months.

Figure 4b. The effects of Disposal Option and Frequency of Use on Discount, at low and high Attachment Tendencies, for 24-month old laptops (H5)

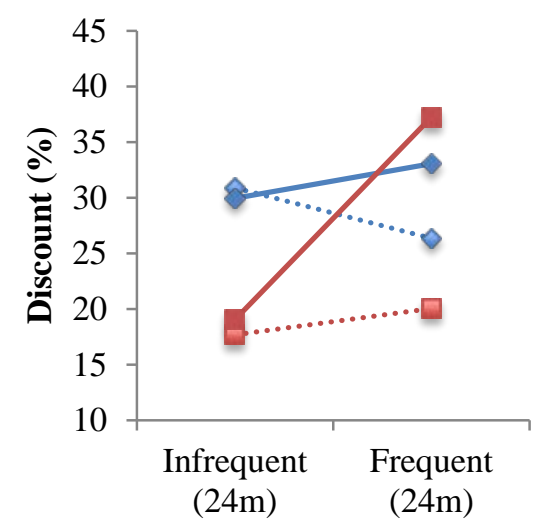

$\ldots \diamond \ldots$ T $($ low AT)

$\cdots \boxminus \cdots$ TC (low AT)

* Disposal Option: T=Trade-in; TC=Trade-in plus Charity. Frequency of Use: Infrequent use; Frequent use. AT=Attachment Tendencies. Product Age: 24m=24-months.

This article is protected by copyright. All rights reserved. 
Figure 5a. The effects of Disposal Option and Frequency of Use on Discount, at low and high Frugality, for 6-month old laptops (H6a, H6b)

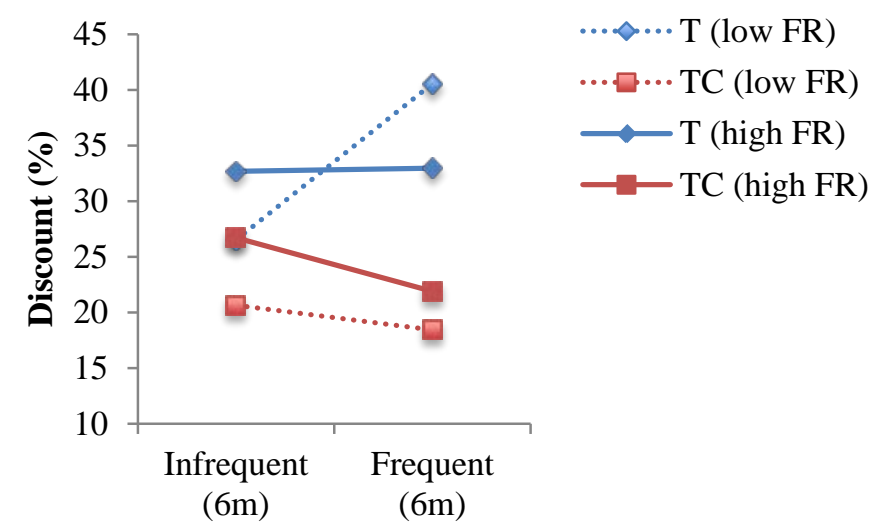

* Disposal Option: T=Trade-in; TC=Trade-in plus Charity. Frequency of Use: Infrequent use; Frequent use. FR=Frugality. Product Age: 6m=6-months.

Figure 5b. The effects of Disposal Option and Frequency of Use on Discount, at low and high Frugality, for 24-month old laptops (H6a, H6b)

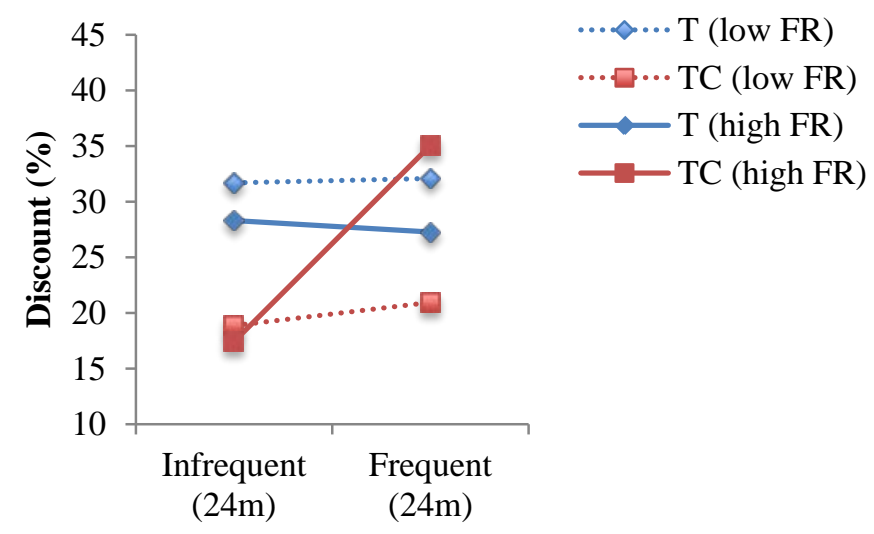

* Disposal Option: T=Trade-in; TC=Trade-in plus Charity. Frequency of Use: Infrequent use; Frequent use. FR=Frugality. Product Age: $24 \mathrm{~m}=24$-months. 


\section{APPENDIX}

\section{Attention Check:}

"Everyone has hobbies. Nevertheless, we would like you to skip this question to show that you are reading carefully".

\section{Frequency of Use variable (Study 2):}

After selecting an important computer, consumers were asked to identify 'why' their computer was important to them, with responses categorized into either: 'Frequent Use' (1): "I use it the most often" ( $n=137,55 \%)$, "I have it with me all of the time ( $n=12,4.8 \%)$ ", and "I have invested the most in this computer" $(n=7,2.8 \%)$; or 'Other' (0): "I use it to perform my most important tasks" ( $n=24,9.6 \%)$, I've owned it for the longest time ( $n=1,0.4 \%)$, None of the above $(n=3,1.2 \%)$, and no response $(n=69,27.6 \%)$. The two categories broadly captured descriptions provided by consumers during the interviews. We then assessed whether consumer's responses adequately represented a 'frequency' of use (1=high, and $0=\mathrm{low})$ using Shih and Venkatesh's (2004) framework, of high use-high variety (frequent use, 1), and low use and/or low variety (other, 0 ). To do this we compared the two categories to consumer responses regarding how often they used their computer across seven tasks (after Shih and Venkatesh, 2004), aggregated into three task groups on the basis of task means (consumers use their computers unequally for different tasks), as follows:

- Employment related activity; and Education (school, college) (Group 1)

- Personal emails to family and friends; Personal information management (health records, recipes, banking); and Social networking (facebook, twitter, blogs) (Group 2)

- Recreation (games); and Entertainment (TV, movies, youtube) (Group 3)

We compared group means as shown in table A1 below. This established a significant difference in means between the two categories across a variety of tasks, supporting our categorization for Frequency of Use.

$\underline{\text { Table A1. Consumer computer use by variable category (Study 2) }}$

\begin{tabular}{lcccc}
\hline & \multicolumn{4}{c}{ Group Means } \\
\cline { 2 - 5 } & $\mathrm{n}$ & Group 1 & Group 2 & Group 3 \\
Frequent Use (1) & 156 & 0.32 & 0.42 & 0.40 \\
Other Use (0) & 94 & 0.19 & 0.31 & 0.25 \\
Sig. of difference & & $0.005^{* *}$ & $0.02^{*}$ & $0.002^{* *}$ \\
\hline $1 * p<0.05, * * p<0.01$. Means were compiled from individual task scores of either low use (0) or high \\
use (1).
\end{tabular}

\section{Manipulation check (study 3)}

We used ANOVA to check the effect of manipulations in Study 3. Consumers assigned to the 6-month old laptop condition had a significantly newer product than consumers in the 24-month old laptop condition ( $p<0.001^{* *} ; M_{6 \text {-months }}=14, M_{24-}$ 
months $=22$ ). Consumers assigned to the infrequent use condition, used their laptop significantly less than those in the frequent use condition $\left(p<0.001^{* *} ; M_{\text {rarely }}=3.0, M\right.$ almost always $=4.2$ ).

Control variables (Study 2 and Study 3):

- Age categories (1-7): 18-24; 25-34; 35-44; 45-54; 55-64; 65 and up; under 18 (we excluded any respondents under 18).

- Income (in \$AUD) (1-9): 0-24,999; 25,000-49,999; 50,000-74,999; 75,00099,999; 100,000-124,999; 125,000-149,999; 150,000-174,999; 175,000-199,999; 200,000 and up.

- Education (1-6): Primary school, some secondary school, some technical school, some/now at university, diploma, degree or higher (Masters, PhD)

- Gender: Male/Female

- Product age (Study 2): number of years you have owned this computer - "1" (6months); “2” (1 year); “3” (2 years); “4” (3 years); “5” (4 years); "6” (5+ years).

- How many computers (Study 2): “1”, etc. through to "6+" (those not owning a computer were excluded).

- How many laptops (Study 3): “0”, “1” etc. through to “7 or more”.

Table A2. Items and measurement validity (Study 2)

\begin{tabular}{|c|c|c|c|c|}
\hline Variable items & $\begin{array}{r}\text { Factor } \\
\text { loading }\end{array}$ & $\begin{array}{r}\text { Variable } \\
\text { reliability }\end{array}$ & $\begin{array}{r}\text { Average } \\
\text { variance } \\
\text { extracted }\end{array}$ & $\begin{array}{r}\text { Square root } \\
\text { of average } \\
\text { extracted }\end{array}$ \\
\hline $\begin{array}{l}\text { Attachment Tendencies }(\mathrm{M}=3.15 \text {, } \\
\mathrm{SD}=1.10 ; \alpha=0.93)\end{array}$ & & 0.930 & 0.769 & 0.877 \\
\hline Getting rid of stuff is hard for me & 0.857 & & & \\
\hline $\begin{array}{l}\text { I tend to hold on to my possessions } \\
\text { Unless I have a really good reason to throw } \\
\text { something away, I keep it }\end{array}$ & $\begin{array}{l}0.898 \\
0.872\end{array}$ & & & \\
\hline I do not like to dispose of possessions & 0.880 & & & \\
\hline $\begin{array}{l}\text { Frugality }(\mathrm{M}=\mathbf{3 . 9 7}, \mathrm{SD}=\mathbf{0 . 8 1} ; \boldsymbol{\alpha}=\mathbf{0 . 9 0}) \\
\text { I believe in being careful in how I spend } \\
\text { my money }\end{array}$ & 0.803 & 0.904 & 0.703 & 0.838 \\
\hline $\begin{array}{l}\text { I discipline myself to get the most from my } \\
\text { money }\end{array}$ & 0.790 & & & \\
\hline $\begin{array}{l}\text { I am willing to wait on a purchase I want so } \\
\text { that I can save money } \\
\text { There are things I resist buying today so I } \\
\text { can save for tomorrow }\end{array}$ & 0.903 & & & \\
\hline $\begin{array}{l}\text { Product Retention }(\mathrm{M}=3.65, \mathrm{SD}=1.03 ; \alpha= \\
0.78)\end{array}$ & & 0.788 & 0.556 & 0.746 \\
\hline I would always like to keep my computer & 0.659 & & & \\
\hline I can't imagine selling my computer & 0.859 & & & \\
\hline My computer is irreplaceable & 0.705 & & & \\
\hline
\end{tabular}

This article is protected by copyright. All rights reserved. 
All items loaded to intended variables at $>0.60$ (Nunnally and Bernstein, 1994); composite reliability scores at >0.70; AVE scores at $>0.50$ (Fornell and Larcker, 1981); square root of the AVE exceeded all corresponding correlations (Fornell and Larcker, 1981).

\section{Table A3. Further illustrative quotes from interviews (Study 1): Anxiety theme}

"Giving it to a recycler? If I could not give it to an underprivileged person then okay but only if it is recycled properly"

"If I was told that a person who needed the laptop was under-privileged and my friend was not, then certainly the under-privileged person would get the laptop. But if I did not know them then no, I would not trust them because I would have in the back of mind, where is that laptop? Did it reach the right person?”

"There are certain agencies that if you donate it to them then you know it will go into the proper hands. I would not like the thinking about where it goes."

"If I got rid of it I was going to take it to the [landfill] but I wasn't sure if someone could grab hold of it and access things that I've had, like information on it ... If I knew where to take it, like if someone said 'you can dispose of your things here' and it could be wiped clean.” 


\section{University Library}

\section{- M M N E R VA A gateway to Melbourne's research publications}

Minerva Access is the Institutional Repository of The University of Melbourne

Author/s:

Simpson, D;Power, D;Riach, K;Tsarenko, Y

Title:

Consumer motivation for product disposal and its role in acquiring products for reuse

Date:

2019-10-01

Citation:

Simpson, D., Power, D., Riach, K. \& Tsarenko, Y. (2019). Consumer motivation for product disposal and its role in acquiring products for reuse. Journal of Operations Management, 65 (7), pp.612-635. https://doi.org/10.1002/joom.1049.

Persistent Link:

http://hdl.handle.net/11343/286886 